\title{
Caloric materials near ferroic phase transitions
}

X. Moya ${ }^{1,2}$, S. Kar-Narayan ${ }^{1}$ and N. D. Mathur ${ }^{1}$

${ }^{1}$ Department of Materials Science, University of Cambridge, 27 Charles Babbage Road, Cambridge CB3 0FS, UK

${ }^{2}$ Facultat de Física, Departament d'Estructura i Constituents de la Matèria, Universitat de Barcelona, Martí i Franquès 1, E-08028 Barcelona, Catalonia, Spain

A magnetically, electrically or mechanically responsive material can undergo significant thermal changes near a ferroic phase transition when its order parameter is modified by the conjugate applied field. The resulting magnetocaloric, electrocaloric and mechanocaloric (elastocaloric or barocaloric) effects are compared here in terms of history, experimental method, performance and prospective cooling applications.

Indian rubber was found to heat when rapidly stretched at the lips of blind natural philosopher John Gough in early nineteenth century England ${ }^{1}$. If this heat is dissipated, the rubber then cools when the uniaxial stress is released. Elastocaloric $(\mathrm{eC})$ effects such as these were reported for various materials by Joule ${ }^{2}$ in 1859 , shortly after Lord Kelvin had provided a thermodynamic interpretation ${ }^{3}$ that he subsequently generalised ${ }^{4}$ to predict what would later be called magnetocaloric (MC) and electrocaloric (EC) effects, 
driven by magnetic and electric fields. Experimental research into these caloric phenomena is now blossoming, and prototype heat pumps are under active development, so a review is therefore timely. Barocaloric $(\mathrm{BC})$ effects driven by isotropic stress also form part of the story, leading us to coin the term "mechanocaloric" $(\mathrm{mC})$ for a collective description of eC and $\mathrm{BC}$ effects (see Box 1 for a glossary of terms and symbols).

Warburg is widely credited with the first experimental observation of MC effects. However, as reported recently ${ }^{5}$, he made no such claim in his 1881 paper $^{6}$ on room-temperature iron, measured well below the Curie temperature. Instead, he described irreversible heating due to magnetic hysteresis, and he did not claim this magnetically driven thermal effect to be novel given that he cited previous work. The 1917 report $^{7}$ of Weiss and Piccard, on nickel near the Curie temperature, represents the first observation of reversible MC effects, but reversibility was not demonstrated therein. Weiss and Piccard coined "magnétocalorique" in French, and merely mentioned in passing that the sample cooled below the starting temperature if the applied field was removed after the magnetically generated heat had dissipated.

Just after the 1930 experimental observation of electrically analogous EC effects in Rochelle salt ${ }^{8}$, MC cooling in paramagnetic salts was exploited to approach absolute zero $^{9}$. This cryogenic technique led Giauque to the 1949 Nobel Prize for chemistry, and is still exploited in scientific laboratories to achieve millikelvin temperatures over finite hold times. Sustained MC cooling was first demonstrated ${ }^{10,11}$ in the 1950 s using paramagnetic salts below $1 \mathrm{~K}$, and then near room temperature in 1976 by exploiting the 
ferromagnetic phase transition in gadolinium ${ }^{12}$. This latter work by Brown was seminal, as it introduced regenerators, which dramatically increase the temperature span that can be achieved in a prototype heat pump based on any of the three caloric effects (see Prototypes and applications). As a result, research publications on MC cooling began to increase (inset, Fig. 1).

The nineteen eighties, nineties and subsequent noughties saw, respectively, the observation of large $\mathrm{mC}, \mathrm{MC}$ and $\mathrm{EC}$ effects near structural phase transitions. These three so-called "giant" caloric effects were thus reported in the same order as the three caloric effects. The giant $\mathrm{mC}$ effects were found ${ }^{13}$ in the shape-memory alloy $\mathrm{Cu}_{69.6} \mathrm{Al}_{27.7} \mathrm{Ni}_{2.7}$ as part of a thermodynamic study into martensitic transitions; the giant MC effects were found ${ }^{14}$ near the magnetostructural transition in metallic $\mathrm{Fe}_{49} \mathrm{Rh}_{51}$; and the giant $\mathrm{EC}$ effects were found near the ferroelectric transition in films of the ceramic $\mathrm{PbZr}_{0.95} \mathrm{Ti}_{0.05} \mathrm{O}_{3}$ (ref. 15) and later two fluorinated polymers ${ }^{16}$. Based on citation data, it appears that the discovery of giant $\mathrm{EC}$ effects ${ }^{15,16}$ was unique in triggering a significant increase in research activity. Recent research into MC effects was instead primarily stimulated by the 1997 report $^{17}$ of giant $\mathrm{MC}$ effects in $\mathrm{Gd}_{5} \mathrm{Si}_{2} \mathrm{Ge}_{2}$. The current resurgence of $\mathrm{mC}$ research $^{18-20}$ may have been stimulated by work on the other two caloric effects. Publication trends are shown in Fig. 1. A selection of giant caloric effects are summarised in Tables 1-3 and Fig. 2, using the conventional but arbitrary practice of mass normalization. For the same materials, Supplementary Information presents the relevant data with mass, molar and volume normalizations, first without (Figs S1-S3, Tables S1-S3) and then with (Tables S4-S6) additional normalization by applied field. 
This review is inspired by the now parallel development of all three caloric effects, which have been studied separately until very recently ${ }^{21}$. A caloric material that can develop thermal changes in response to more than one species of driving field is multicaloric. There are likely to be many multicaloric materials given that the structural degree of freedom, which underpins $\mathrm{mC}$ effects, is typically responsible for enhancing $\mathrm{MC}$ and $\mathrm{EC}$ effects. However, MC and EC effects have not been reported in the same material, just as it is rare to find multiferroic materials showing both ferromagnetism and ferroelectricity.

Our focus will be primarily scientific, but we will discuss prototype cooling devices based on all three caloric effects, and we will discuss the challenges that must be overcome in order to permit the possibility of applications. Several reviews describe MC materials extensively (e.g. refs 22-26), so our section on these is deliberately brief. Along with a book ${ }^{27}$, several reviews on EC materials have recently appeared (e.g. refs 28-30) and most of these are brief. We have tended to cite a limited selection of original reports and only a few review articles, as the permitted number of cited references is limited.

\section{Measurement protocols}

If a caloric material at some given starting temperature experiences a change of applied field, then one may evaluate adiabatic temperature change $\Delta T$, isothermal entropy change $\Delta S$, and isothermal heat $Q$ (Table 4). Direct measurements are ultimately desirable, but can be challenging, so it is common practice to use indirect and quasi-direct methods (Box 2). Ideally, both $\Delta T$ and $Q$ should be measured independently near the phase transitions at which caloric effects peak, as their interconversion via $Q \simeq c \Delta T$ is 
compromised by the assumption that specific heat capacity $c$ does not depend on temperature and field. Entropy cannot be measured directly, but changes in this state variable $\Delta S$ are commonly reported instead of $Q$.

Direct measurements of temperature change may be performed using contact or non-contact thermometry, with or without spatial resolution. However, direct measurements of heat are rare, as few existing calorimeters permit the application of variable magnetic, electric or stress fields. Values of $\Delta T$ and $Q$ that are directly measured on heating and cooling can be underestimated due to heat leaks between samples and surroundings, especially in the case of BC materials surrounded by a pressure medium. In calorimetry, the measured heat does not correspond to $Q$ if the driving field changes too quickly for isothermal conditions to be maintained, and errors arise if the sensor is not accurately calibrated on the measurement timescale or if the sensor makes poor thermal contact with the sample. If there is eddy-current heating (MC materials), Joule heating (EC materials) or frictional heating (mC materials), then values of $\Delta T$ and $Q$ obtained on cooling will tend to be more conservative than values obtained on heating. Direct measurements are therefore challenging, as the issues discussed here have the potential to compromise caloric data (Tables 1-3, Fig. 2).

For $\mathrm{mC}$ materials, direct measurements of $\Delta T$ are routine but non-trivial. Thermometers have been used when varying isotropic ${ }^{31-34}$ or uniaxial ${ }^{13,35-37}$ stress, and infra-red cameras have been used when varying uniaxial stress to image bulk samples ${ }^{36,38}$ or a free-standing eC film ${ }^{39}$. Quasi-direct measurements have also been used to study mC materials ${ }^{20,31,32}$. 
However, indirect $\mathrm{mC}$ measurements are rare ${ }^{19,40}$, even though they are typically not compromised by heat leaks. If the applied stress varies rapidly then heat leaks can be minimised when making direct measurements of $\Delta T$. Rapid changes in stress are difficult to achieve when increasing hydrostatic pressure, but are otherwise feasible, and could in future be realised using on-chip cantilevers. Only a small force would be required, just as only a small voltage is required to drive EC effects in films ${ }^{15}$.

Indirect MC measurements are common because direct $\mathrm{MC}$ measurements are considered challenging ${ }^{22}$. This is partly because it is necessary to consider the unwanted influence of driving fields on thermal sensors, but primarily because large changes in driving field $\left(\mu_{0} \Delta H>1 \mathrm{~T}\right)$ must occur faster than the timescale on which heat can leak. If this adiabatic limit is approached, e.g. using a pulsed field, then measurements of magnetization alone are sufficient ${ }^{41}$ to calculate $\Delta T$. For most giant MC materials, direct and quasi-direct measurements of $\Delta T$ show good agreement (e.g. refs $17 \& 42$ ), but indirect measurements can be compromised if $c$ is assumed to be constant and if there is significant thermal hysteresis. Direct ${ }^{43}$ and quasi-direct ${ }^{44}$ MC measurements of $Q$ are rare, but they tend to agree with indirect $\mathrm{MC}$ measurements obtained via $Q=T \Delta S$. Thermal imaging data for MC phenomena are even rarer ${ }^{45}$.

For bulk EC materials that display negligible ${ }^{46-48}$ or substantial ${ }^{49}$ field hysteresis, indirect thermal measurements agree well with directly measured data, despite low sample thermal conductivities. For films, which display the largest EC effects, indirect measurements ${ }^{15,16}$ dominate the literature because direct measurements are challenging 
for two reasons. First, active film volume is small as electrical breakdown is limited by reducing both film thickness and active area. Second, substrates have high thermal masses. However, values of $|\Delta T|$ in EC films have been directly measured, using small-bead thermistors attached to free-standing polymer membranes ${ }^{50,51}$, and using a larger resistance thermometer attached to the terminal of a multilayer capacitor (MLC) ${ }^{52}$. These direct measurements confirmed indirect measurements for ergodic systems ${ }^{50,52}$, whereas the failure to achieve any such confirmation for a non-ergodic relaxor ferroelectric ${ }^{51}$ could possibly be rectified via suitable measurement protocols. Direct EC measurements of macroscopic samples have also been achieved using an infra-red camera and a scanning-probe tip containing a resistance thermometer ${ }^{53}$. It is possible that the latter technique may be able to detect EC effects in films with substrates present, enabling rapid characterization of large EC effects.

To avoid breakdown and ageing in both $\mathrm{EC}$ and $\mathrm{mC}$ materials, it is necessary to be conservative when applying the driving field, but to achieve large caloric effects it is necessary to be bold. This dilemma appears to go unreported, even though reliability issues are well known in ferroelectrics, and even though it represents a significant technological issue given that the performance reported in scientific publications likely overestimates the performance that could reliably be achieved at some fraction of the breakdown field. 


\section{Magnetocaloric materials}

At finite temperatures, thermal energy precludes any significant field-driven reduction in the molar entropy $R \ln (2 J+1)$ of independent magnetic moments $(J$ is the angular momentum quantum number for each moment, $R$ is the universal gas constant). However, near finite-temperature magnetic phase transitions, laboratory fields corresponding to several tesla can drive substantial MC effects, as seen in the latter half of the twentieth century using crystalline and amorphous materials based on rare-earth and transition-metal elements ${ }^{54}$. These observations were initially exploited for the study of phase transitions and magnetic interactions, but the 1976 refrigerator prototype ${ }^{12}$ based on gadolinium sparked interest in cooling applications near room temperature.

Even today, the active material in most prototype heat pumps remains gadolinium ${ }^{55}$, as the large magnetization $\left(\sim 7.5 \mu_{\mathrm{B}} / \mathrm{Gd}\right)$ affords large anhysteretic $\mathrm{MC}$ effects near the $294 \mathrm{~K}$ second-order ferromagnetic transition in this readily available material ${ }^{12,42}$. Prototype heat pumps have barely exploited the "giant" MC materials that show slightly larger MC effects near room-temperature first-order magnetostructural phase transitions (Table 1, Fig. 2). These transitions may be conventional or inverse, may arise between states that are magnetically ordered and states that are magnetically ordered or disordered, and may involve changes of symmetry or just volume. The structural degree of freedom is key to giant MC effects, as it more than compensates the dilution of the high-moment elements. It can therefore be used to tune giant MC effects (see Tuning section), and it permits $\mathrm{mC}$ effects in giant $\mathrm{MC}$ materials ${ }^{20,31,32,56,57}$. 
It is possible to enhance aspects of MC performance by exploiting structural variations on different length scales. At the unit-cell level, one may exploit the different mechanistic roles of the different layers via first-principles design ${ }^{58}$. On longer length scales, superlattices $^{59}$ and composites ${ }^{60}$ combining more than one MC composition can increase the range of operating temperatures, as can inhomogeneous strain ${ }^{61}$. On even longer length scales, the introduction of a metallic phase permits good thermal conductivity ${ }^{62}$, just as metallic electrodes carry heat between EC layers and MLC terminals ${ }^{52,63}$. Structural variations can therefore confer various advantages, but they tend to dilute active regions and increase hysteresis. Hysteresis may therefore be reduced by suppressing inhomogenous strain, as shown using porous ${ }^{64}$ or fragmented ${ }^{65}$ samples, whose large surface area-to-volume ratios facilitate heat transfer with fluids, e.g. in MC beds.

It is also possible to improve aspects of MC performance via chemical tuning. Alloying $\mathrm{Gd}_{5} \mathrm{Si}_{2} \mathrm{Ge}_{2}$ with iron ${ }^{66}$ reduces magnetic hysteresis by $90 \%$ and broadens but shortens the peak in $|\Delta S(T)|$; the interstitial introduction of mobile hydrogen to $\mathrm{La}\left(\mathrm{Fe}_{1-x} \mathrm{Si}_{x}\right)_{13}$ increases the operating temperature from $195 \mathrm{~K}$ to $323 \mathrm{~K}$ without compromising the MC effect ${ }^{67}$; and tuning sample composition to merge magnetic and structural transitions can create new magnetostructural transitions for the study of MC effects ${ }^{68}$. 


\section{Electrocaloric materials}

The EC effect is the converse of the pyroelectric effect in which changes of temperature modify electrical polarization. Today, pyroelectricity is exploited in applications that include infra-red cameras, burglar alarms and fingerprint sensors. However, its influence was recorded far earlier by the ancient Greek philosopher Theophrastus, who observed that heated rocks of tourmaline attract debris. EC effects were first reported ${ }^{8}$ two millenia later in 1930, via qualitative measurements that formed part of a wider investigation into Rochelle salt $\left(\mathrm{NaKC}_{4} \mathrm{H}_{4} \mathrm{O}_{6} \cdot 4 \mathrm{H}_{2} \mathrm{O}\right)$, the piezoelectric material in which ferroelectricity had been discovered ten years earlier, following more than two centuries of medicinal use. There was subsequently very little EC research until the 1960s, but by the end of that decade there had been quantitative EC studies on hydrogen-bonded ferroelectrics, ceramic perovskites and doped halides.

Before discussing EC developments after 1930, let us compare the performance that might be expected of hydrogen-bonded ferroelectrics and ceramic perovskites, which unlike doped halides show phase transitions, and therefore significant EC effects well away from absolute zero. Ceramic perovskites have traditionally been understood to show purely displacive ferroelectric transitions associated with small entropy changes. Hydrogen-bonded ferroelectrics have traditionally been understood to show purely order-disorder phase transitions associated with large entropy changes. However, there is evidence that hydrogen-bonded ferroelectric transitions show some displacive character $^{69}$, and there is evidence that ferroelectric transitions in perovskites possess an order-disorder character that may be understood in terms of the number of directions 
along which instantaneous cation displacements are permitted ${ }^{70}$. As discussed below, the relative performance of ceramic perovskites and hydrogen-bonded ferroelectrics is therefore blurred, especially because even purely displacive transitions may show large entropy changes associated with soft polar vibrational modes.

Following the 1930 discovery paper $^{8}$, we are led to believe that the US and Japanese navies explored the possibility of using EC effects to cool submarines during World War II (Kenji Uchino, private communication), but no EC reports were published until 1950, when an indirect measurement of $|\Delta T| \sim 1 \mathrm{~K}$ in response to $|\Delta E|=10 \mathrm{kV} \mathrm{cm}^{-1}$ was reported near the $\sim 125 \mathrm{~K}$ ferroelectric transition of potassium dihydrogen phosphate $(\mathrm{KDP})^{71}$. Other hydrogen-bonded ferroelectrics were subsequently studied in the $1960 \mathrm{~s}$, and a similar strength response $|\Delta T / \Delta E|$ was found in triglycine sulfate (TGS) ${ }^{72}$, where $|\Delta T| \sim 0.1 \mathrm{~K}$ was produced by $|\Delta E|=1.7 \mathrm{kV} \mathrm{cm}^{-1}$ near $\sim 323 \mathrm{~K}$. However, the discovery material Rochelle salt was found ${ }^{48}$ to display a grossly inferior response of just $|\Delta T| \sim$ $4 \mathrm{mK}$ in $|\Delta E| \sim 1.4 \mathrm{kV} \mathrm{cm}^{-1}$ at $295 \mathrm{~K}$.

Also in the 1960s, various dielectric materials were investigated for cryogenic EC refrigeration, e.g. the ceramic perovskite $\mathrm{SrTiO}_{3}\left(|\Delta E|=7 \mathrm{kV} \mathrm{cm}^{-1}\right.$ produced $|\Delta T| \sim 0.3 \mathrm{~K}$ near $11.5 \mathrm{~K})^{73}$, and $\mathrm{KCl}$ with dipoles comprising $\mathrm{K}^{+}$vacancies paired with $\mathrm{Li}^{+}$dopants $\left(|\Delta E|=41 \mathrm{kV} \mathrm{cm}^{-1} \text { produced }|\Delta T| \sim 0.5 \mathrm{~K} \text { near } 2 \mathrm{~K}\right)^{74}$. Temperatures below $1 \mathrm{~K}$ could be achieved $^{75}$ by varying an electric field that lifted the degeneracy of dipolar hydroxyl impurities in $\mathrm{KCl}$, but the most highly cited work on EC effects until 2011 remained the 1965 report $^{74}$ on Li-doped $\mathrm{KCl}$. 
By the 1960s, ferroelectricity had also been discovered in ceramic perovskites. Materials such as $\mathrm{BaTiO}_{3}$ (ref. 76) and doped/undoped $\mathrm{Pb}(\mathrm{Zr}, \mathrm{Ti}) \mathrm{O}_{3}$ (ref. 46) were found to display similar EC effects to $\mathrm{KDP}\left(|\Delta T| \sim 1 \mathrm{~K} \text { in }|\Delta E| \sim 10 \mathrm{kV} \mathrm{cm}^{-1}\right)^{71}$, but at room temperature and above. Over the subsequent decades, a range of perovskite compositions was investigated, but there were no significant improvements in EC performance. However, variations in the doping ${ }^{77,78}$ and $\mathrm{B}$-site disorder ${ }^{78}$ of $\mathrm{PbSc}_{0.5} \mathrm{Ta}_{0.5} \mathrm{O}_{3}$ permitted $|\Delta T|=1-1.8 \mathrm{~K}$ to be obtained with $|\Delta E|=20-30 \mathrm{kV} \mathrm{cm}^{-1}$ in a wide range of temperatures near room temperature $(210-310 \mathrm{~K})$. The largest EC temperature change in bulk materials remained for a long time the directly measured value of $|\Delta T|=2.5 \mathrm{~K}$ in response to $|\Delta E|=30 \mathrm{kV} \mathrm{cm}^{-1}$, near the $434 \mathrm{~K}$ Curie temperature of $\mathrm{Pb}_{0.99} \mathrm{Nb}_{0.02}\left(\mathrm{Zr}_{0.75} \mathrm{Sn}_{0.20} \mathrm{Ti}_{0.05}\right)_{0.98} \mathrm{O}_{3}$ (ref. 47). However, it was recently found that $|\Delta E|=130 \mathrm{kV} \mathrm{cm}^{-1}$ in $\mathrm{Ba}_{0.65} \mathrm{Sr}_{0.35} \mathrm{Ti}_{0.997} \mathrm{Mn}_{0.003} \mathrm{O}_{3}$ ceramics prepared by spark plasma sintering produced ${ }^{79}|\Delta T|=3.1 \mathrm{~K}$ near $293 \mathrm{~K}$, and that $|\Delta E|=160 \mathrm{kV} \mathrm{cm}^{-1}$ in bulk $0.9 \mathrm{PbMg}_{1 / 3} \mathrm{Nb}_{2 / 3} \mathrm{O}_{3}-0.1 \mathrm{PbTiO}_{3}(0.9 \mathrm{PMN}-0.1 \mathrm{PT})$ thinned to $80 \mu \mathrm{m}$ produced $|\Delta T|=3.5 \mathrm{~K}$ near 400 K [H. Uršič, B. Rožič, Z. Kutnjak, J. Holc, M. Kosec, private communication].

EC studies have been resurgent since 2006 (Fig. 1), when 350 nm-thick sol-gel films of the ceramic $\mathrm{PbZr}_{0.95} \mathrm{Ti}_{0.05} \mathrm{O}_{3}$ were found to show large values of $|\Delta T|=12 \mathrm{~K}$, in response to relatively large values of $|\Delta E|=480 \mathrm{kV} \mathrm{cm}^{-1}$ near the $495 \mathrm{~K}^{\text {Curie temperature }}{ }^{15}$. The EC effects in this film were thus driven harder than they could be driven in any bulk sample, by exploiting the generic inverse relationship between breakdown field and sample thickness. Shortly thereafter, similar values of $|\Delta T|=12.5 \mathrm{~K}$ were reported ${ }^{16}$ nearer to room temperature for two types of $\sim 1 \mu \mathrm{m}$-thick spin-cast polymer film, namely 
the ferroelectric poly(vinylidene fluoride-trifluoroethylene) $[\mathrm{P}(\mathrm{VDF}-\mathrm{TrFE})]$ driven at $353 \mathrm{~K}$ with $|\Delta E|=2090 \mathrm{kV} \mathrm{cm}^{-1}$, and the relaxor $\mathrm{P}(\mathrm{VDF}-\mathrm{TrFE}-\mathrm{CFE})$ driven at $328 \mathrm{~K}$ with $|\Delta E|=3070 \mathrm{kV} \mathrm{cm}^{-1}$ (CFE is chlorofluoroethylene). The polymer films thus required larger driving fields than the ceramic films ${ }^{15}$, but they showed a five-fold improvement of mass-normalized EC heat $|Q|$. However, the volume-normalized values of $|Q|$ are similar for these ceramic and polymer films (Supplementary Fig. S3 and Table S2) such that the ceramic films outperform the polymer films in terms of the resulting values of $|Q / \Delta E|$ (Supplementary Table S5) ${ }^{80}$.

Large EC effects have now been reported in various ceramic and polymer films (Table 2, Fig. 2), with relaxors tending to show broad transitions. Large EC effects were confirmed via direct $|\Delta T| \sim 12 \mathrm{~K}$ measurements of polymer films ${ }^{50,51}$ (see Measurement protocols). Direct measurements also reveal that a free-standing $65 \mu \mathrm{m}$-thick film ${ }^{81}$ of 0.65PMN-0.35PT, and a bulk platelet of similar composition and thickness ${ }^{82}$, show similar EC effects. This circumstantially suggests that the EC performance of ceramic samples does not depend strongly on processing details, whereas this is unlikely to be the case for polymers whose crystallinity is typically partial.

Microscopic insight into the EC effect would likely benefit from wider studies of crystallographically textured films, epitaxial films and single crystals. Single crystals can possess particularly sharp phase transitions that may be driven by relatively small electric fields, yielding giant EC strengths ${ }^{49}|Q / \Delta E|,|\Delta S / \Delta E|$ and perhaps $|\Delta T / \Delta E|$. A better understanding of EC effects could permit upper bounds on EC performance to be 
predicted $^{83}$, but the possible existence of edge layers ${ }^{80}$ could complicate matters. One might also investigate inverse EC effects ${ }^{84}$, processing routes that increase the breakdown fields in polycrystalline samples, and alternative ferroelectric materials such as liquid crystals and solid $\mathrm{HCl}$.

\section{Mechanocaloric materials}

Giant $\mathrm{mC}$ effects may be driven near structural phase transitions, and therefore arise in most giant $\mathrm{MC}$ and $\mathrm{EC}$ materials, as well as in materials that display purely structural phase transitions (Table 3, Fig. 2). Giant $\mathrm{mC}$ effects may be also driven reversibly well away from the hysteretic regime of first-order transitions ${ }^{13,19,35}$, unlike MC effects for which the applied field is limited, and unlike EC effects for which breakdown may occur. Therefore giant $\mathrm{mC}$ effects in a single material may be driven reversibly over a wide range of temperatures, cf. relaxor ferroelectrics. Below we discuss the small body of work on eC effects due to changes of uniaxial stress $\left|\Delta \sigma_{\mathrm{u}}\right|$. We will then discuss the relatively recent work on $\mathrm{BC}$ effects due to changes of isotropic stress, i.e. changes of hydrostatic pressure $|\Delta p|$. Both non-ferroic and ferroic materials will feature in our discussions.

\section{Elastocaloric materials}

Over 150 years ago, Joule ${ }^{2}$ reported that metals and dry woods show room-temperature eC effects of $|\Delta T| \sim 0.2 \mathrm{~K}$, due to reversible elastic heat. He also reported that tensile (compressive) stress produced inverse (conventional) eC effects of similar strength in rubber, due to structural phase transitions associated with polymer chain alignment. 
Around one century later, in the 1960s, hydroxyl-doped $\mathrm{KCl}$ was proposed for cryogenic $\mathrm{eC}$ cooling, in the same report ${ }^{75}$ that proposed cryogenic EC cooling using the same material (see Electrocaloric materials). However, on starting at $1.4 \mathrm{~K}$ and removing $12 \mathrm{GPa}$ of compressive stress, frictional heating reduced an expected cooling of $0.23 \mathrm{~K}$ to $0.13 \mathrm{~K}$.

More recently, order-of-magnitude larger eC effects due to order-of-magnitude smaller stresses have been observed near low-temperature structural phase transitions in rare-earth compounds such as $\mathrm{HoAs}$ (ref. 34), $\mathrm{Ce}_{3} \mathrm{Pd}_{20} \mathrm{Ge}_{6}$ (ref. 34), and $\mathrm{CeSb}$ (ref. 85). Even larger eC effects near room-temperature structural phase transitions have been observed in shape-memory copper-based alloys $(|\Delta T|=12-15 \mathrm{~K}$ for $\left.\left|\Delta \sigma_{\mathrm{u}}\right| \sim 0.1-0.2 \mathrm{GPa}\right)^{13,19,35}$ and $\mathrm{Fe}_{68.8} \mathrm{Pd}_{31.2}$ alloys $\left(|\Delta T|=3 \mathrm{~K} \text { for }\left|\Delta \sigma_{\mathrm{u}}\right| \sim 0.2 \mathrm{GPa}\right)^{86}$, and predicted in the oxyfluoride $\left(\mathrm{NH}_{4}\right)_{2} \mathrm{MoO}_{2} \mathrm{~F}_{4}\left(|\Delta T| \sim 15 \mathrm{~K}\right.$ for $\left|\Delta \sigma_{\mathrm{u}}\right| \sim 9 \mathrm{GPa}$ or $|\Delta p|=0.7 \mathrm{GPa})^{87}$. These eC effects are stronger than those arising near the magnetostructural phase transition in $\mathrm{Fe}_{49} \mathrm{Rh}_{51}\left(|\Delta T| \sim 5 \mathrm{~K} \text { for }\left|\Delta \sigma_{\mathrm{u}}\right| \sim 0.50 \mathrm{GPa}\right)^{56,57}$, which was not mechanically driven in full given that it supports a slightly larger MC effect $^{56}$ of $|\Delta T| \sim 8 \mathrm{~K}$. Prototypical shape-memory alloys of Ni-Ti show the largest eC effects $\left(|\Delta T| \sim 20-40 \mathrm{~K} \text { for }\left|\Delta \sigma_{\mathrm{u}}\right| \sim 0.8 \mathrm{GPa}\right)^{36-38}$, and it has been shown that chemical doping can suppress mechanical fatigue ${ }^{39}$, and both hysteresis and thermal fatigue ${ }^{88}$.

\section{Barocaloric materials}

In 1998, K. Alex Müller and co-workers reported a small inverse BC effect at $350 \mathrm{~K}$, near a structural transition in the polycrystalline nickelate $\operatorname{Pr}_{0.66} \mathrm{Laa}_{0.34} \mathrm{NiO}_{3}(\Delta T \sim-0.2 \mathrm{~K}$ 
on applying $\Delta p=0.5 \mathrm{GPa})^{33}$. However, the cooling associated with the transition was strongly diminished to the measured value by elastic heat arising from the compression of the interconvertible phases on either side of the transition, so larger pressures $(|\Delta p|>$ $1 \mathrm{GPa}$ ) increased rather than decreased sample temperature. This elastic heat was accessible over a wide range of temperatures, and may well be reversible assuming no intergranular friction ${ }^{34}$. It is no surprise that $\mathrm{BC}$ effects associated with a phase transition may be thus dwarfed by elastic heat, given that large and reversible $\mathrm{BC}$ effects have been observed in non-ferroic poly(methyl methacrylate) at finite temperatures (starting at $368 \mathrm{~K},|\Delta T| \sim 9 \mathrm{~K}$ for $|\Delta p|=0.18 \mathrm{GPa})^{89}$.

However, $\mathrm{BC}$ effects due to first-order magnetostructural transitions typically dominate elastic heat. Driving one such transition with $\Delta p=-0.48 \mathrm{GPa}$ at $60 \mathrm{~K}$ caused $^{34}$ $\Delta T \sim-0.5 \mathrm{~K}$ in the polycrystalline rare-earth compound $\mathrm{EuNi}_{2}\left(\mathrm{Si}_{0.15} \mathrm{Ge}_{0.85}\right)_{2}$, and this measured cooling may be an order-of-magnitude underestimate due to heat leaks ${ }^{34}$. Large $\mathrm{BC}$ effects have now been observed ${ }^{20}$ near room temperature, in a superelastic magnetic alloy of $\mathrm{Ni}_{49.26} \mathrm{Mn}_{36.08} \mathrm{In}_{14.66}$, where pressure-dependent calorimetry data yielded $|\Delta T| \sim 4.5 \mathrm{~K}$ for $|\Delta p|=0.26 \mathrm{GPa}$. The transition that supports this conventional BC effect also supports an inverse $\mathrm{MC}$ effect ${ }^{20}$, whereas the intermetallic $\mathrm{LaFe}_{11.33} \mathrm{Co}_{0.47} \mathrm{Si}_{1.2}$ shows inverse $\mathrm{BC}$ effects and conventional $\mathrm{MC}$ effects ${ }^{32}$. Moreover, the giant $\mathrm{MC}$ material $\mathrm{Gd}_{5} \mathrm{Si}_{2} \mathrm{Ge}_{2}$ shows conventional MC effects and conventional BC effects ${ }^{31}$. Therefore, as expected, giant $\mathrm{MC}$ materials represent fertile ground for the study of $\mathrm{mC}$ effects. 


\section{Tuning caloric materials with stress}

Caloric effects driven by one field may be modified when a second type of field is held fixed. For example, MC effects in ferromagnetic films peak at a Curie temperature that may be modified by applying an electric field via a gate or a piezoelectric substrate. Of particular interest here are giant MC and EC effects arising near structural phase transitions that may be tuned with stress. Stress can modify the magnitude of a caloric effect, the operating temperature, the order of the transition, and any hysteretic losses arising. Stress can even create phase transitions in non-ferroic and ferroic systems, permitting large caloric effects to be explored in an expanded range of materials.

Most reports on caloric effects under mechanical boundary conditions focus on MC effects under hydrostatic pressure ${ }^{90-92}$. Pressure modifies the height, the width and the position of the peak in $|\Delta S(T)|$. For giant MC materials, the large shift in peak position ${ }^{91,92}$ (at typically $\left.\pm(50-150) \mathrm{K} \mathrm{GPa}^{-1}\right)$ is consistent with large $\mathrm{BC}$ effects. If a first-order magnetostructural transition is magnetically driven forwards and backwards at different pressures, then hysteretic losses associated with the resulting MC effects can be significantly reduced, e.g. by one order of magnitude in $\mathrm{Ni}_{45.2} \mathrm{Mn}_{36.7} \mathrm{In}_{13} \mathrm{Co}_{5.1}$ (ref. 93). Separately, a first-order magnetostructural transition can be created, rather than modified, by using pressure to merge a second-order magnetic transition with a first-order structural transition, as shown ${ }^{94}$ for $\mathrm{Tb}_{5} \mathrm{Si}_{2} \mathrm{Ge}_{2}$ where $\Delta p \sim 1 \mathrm{GPa}$ increases the magnitude of the peak MC effect by $\sim 75 \%$. 
The effect of pressure on ferroelectric phase transitions in perovskites was studied over half a century ago ${ }^{95}$, but tuning peak EC effects with pressure has not been demonstrated. However, this would be attractive as the pressure-induced suppression of typically high transition temperatures would portend room-temperature effects. For example, the $\sim 400 \mathrm{~K}$ Curie temperature of $\mathrm{BaTiO}_{3}$ is suppressed ${ }^{95}$ at around $-50 \mathrm{~K} \mathrm{GPa}^{-1}$ (implying a significant BC effect). Similarly, it is well known that ferroelectric phase transitions can be dramatically modified via substrate clamping and epitaxial strain $^{96}$. Substrate clamping could be used to tune the giant EC effects seen in sufficiently thin films, eliminating hysteresis by driving first-order transitions second order $^{80,97,98}$. Epitaxial strain may be exploited either in order to enhance EC effects by bringing separate transitions into close proximity ${ }^{99}$, or in order to create transitions in incipient ferroelectric materials (such as $\mathrm{SrTiO}_{3}$ films on $\mathrm{DyScO}_{3}$ substrates at $\sim 300 \mathrm{~K}$ ) ${ }^{100}$. Therefore large anhysteretic finite-temperature EC effects in films are not necessarily restricted to ferroelectric materials that perform likewise in bulk.

MC materials are not normally studied as films, but it has been shown that the magnetostructural transition in a MnAs film is modified by varying epitaxial strain via the choice of GaAs substrate orientation ${ }^{101}$. More recently, the $\sim 200 \mathrm{~K}$ structural phase transition in $\mathrm{BaTiO}_{3}$ substrates was exploited ${ }^{102}$ to vary strain in epitaxial films of the ferromagnetic manganite $\mathrm{La}_{0.7} \mathrm{Ca}_{0.3} \mathrm{MnO}_{3}$. The resulting jump in film magnetization could be modified by an applied magnetic field even though the substrate is non-magnetic. This demonstrated the existence of a strain-mediated feedback mechanism, which was subsequently exploited to yield giant MC effects of similar strength to those seen in giant 
MC materials. This extrinsic MC effect was reversible in the $\sim 6 \mathrm{~K}$-wide transition regime, unlike conventional giant $\mathrm{MC}$ effects, where the full transition may only be driven reversibly at temperatures away from the transition regime. This strategy of materials juxtaposition expands the range of candidate MC materials, and the future use of alternative geometries would increase active volume fractions and interfacial areas.

\section{Prototypes and applications}

Heat pumps based on caloric effects are normally suggested for the cooling of food, medicine, electronics, and the built environment. We will adopt the common focus on refrigeration, but other applications such as air-conditioning may be more forthcoming given that a smaller temperature span is required. Existing refrigerators are based on liquid-vapour transitions, and may operate at up to $60 \%$ of the Carnot efficiency ${ }^{103}$, as confirmed by two independent industry experts with whom we spoke. However, efficiencies are not necessarily always this high, the operating fluids constitute greenhouse gases if released into the atmosphere, and the vapour-compression method is not suitable for small cooling devices or fast start-up times. Therefore the caloric effects reviewed in this article could find traditional or other applications, e.g. by displacing inefficient solid-state Peltier coolers. We will see below that the three different caloric effects lie at different stages of maturity in terms of prototype cooling devices.

A load may be cooled sustainably by cyclically driving caloric effects in order to pump heat periodically or continuously according to system design. The construction of prototype heat pumps is challenging, so the vast majority of caloric research papers focus 
on materials parameters alone. It is common to report field-driven changes in specific entropy $\Delta S$, along with the resulting 'refrigerant capacity' ${ }^{104}$, which is obtained by integrating $\Delta S$ over temperature in order to discriminate against sharp peaks in $|\Delta S(T)|$, as sharp peaks would present a severe design constraint. Although these quantities have no direct bearing on any refrigeration cycle, large entropy changes portend both a large isothermal heat $Q=T \Delta S$ and a large adiabatic change of temperature $\Delta T \simeq(T \Delta S) / c$ (Fig. 2 plots $|\Delta T|$ against $|Q|$ for selected materials). Temperature change drives heat flow and is therefore a key figure of merit as discussed below, whereas the heat flowing in and out of a caloric material influences - but does not uniquely determine - the cooling power of a heat pump. Cooling power is a second key figure of merit for applications that cannot be established from materials parameters alone.

A third key figure of merit for heat pumps running between hot and cold temperatures $T_{\mathrm{h}}$ and $T_{\mathrm{c}}$ is the coefficient of performance (COP), given by cooling power divided by input power. If the COP is divided by the limiting $T_{\mathrm{c}} /\left(T_{\mathrm{h}}-T_{\mathrm{c}}\right)$ value for a Carnot cycle, then the resulting percentage represents the headline efficiency. However, the nomenclature is confusing as the term 'efficiency' most simply describes quantities that compare inputs with outputs, i.e. the COP and the Carnot efficiency but not the headline efficiency. Moreover, the headline efficiency is unduly pessimistic, as a Carnot cycle would require a material capable of developing $|\Delta T|>T_{\mathrm{h}}-T_{\mathrm{c}}$ in order to permit thermal changes to be driven in all four legs. Nevertheless, it is important to maximise $T_{\mathrm{h}}-T_{\mathrm{c}}$, as the net rate of heat flow, from a load at $T_{\text {load }}$ to a sink at $T_{\text {sink }}$, depends on $T_{\mathrm{c}}-T_{\text {load }}$ and $T_{\text {sink }}-T_{\mathrm{h}}$. One might expect values of $|\Delta T|$ to represent upper bounds on values of $T_{\mathrm{h}}-T_{\mathrm{c}}$, 
but values of $T_{\mathrm{h}}-T_{\mathrm{c}}$ can exceed $|\Delta T|$ by as much as a small numerical factor if a regenerator is employed.

The regenerator was first demonstrated in 1976 by Brown ${ }^{12}$, when $T_{\mathrm{h}}-T_{\mathrm{c}}=47 \mathrm{~K}$ was developed between the top and bottom of a fluid column containing Gd plates subjected to cyclical variations in position and field. This is an impressive temperature span given that a field of the magnitude employed $\left(\mu_{0}|\Delta H|=7 \mathrm{~T}\right.$ from a water-cooled electromagnet) yielded just $|\Delta T|=14 \mathrm{~K}$ for Gd alone ${ }^{12}$. An even more impressive value of $T_{\mathrm{h}}-T_{\mathrm{c}}=80 \mathrm{~K}$ was obtained in a similar study shortly thereafter ${ }^{105}$ (Fig. 3).

One may also cyclically displace a heat-exchange fluid through an immobile MC bed. This was described while also describing active magnetic regeneration (AMR) ${ }^{22}$, which was "active" because the temperature profile was stored in the bed rather than the heat-exchange fluid whose heat capacity was low. A range of compositions permitted different regions along the bed to operate near different optimal temperatures ${ }^{22,55,106}$. Employing various compositions has also been suggested for EC elements separated by heat switches ${ }^{107}$ or thermal diodes ${ }^{108}$. Resorting to this level of complexity should ultimately yield larger values of $T_{\mathrm{h}}-T_{\mathrm{c}}$ than a single material can deliver, even if its phase transition is broad (e.g. a relaxor ferroelectric) or strongly field dependent (e.g. mC materials ${ }^{13,19,35}$.

It is possible to define two types of COP for materials instead of heat pumps. The first type of material COP is defined for a specific refrigeration cycle, and therefore represents 
an upper bound on the performance of a putative device exploiting that cycle ${ }^{54,109}$. A value of 30 for this type of materials COP was reported ${ }^{109}$ for eC effects in $\mathrm{Fe}_{49} \mathrm{Rh}_{51}$ when $T_{\mathrm{h}}-T_{\mathrm{c}}=5 \mathrm{~K}$, falling to 20 when $T_{\mathrm{h}}-T_{\mathrm{c}}=10 \mathrm{~K}$. The second type of materials COP compares reversible isothermal heat $Q$ with the corresponding work $W$ done by the driving field ${ }^{80,110}$. We will refer to this as a materials efficiency ${ }^{80} \eta=|Q| /|W|$ rather than a $\mathrm{COP}^{36,110}$, to avoid the possibility of false comparison with the Carnot efficiency that bounds device COP. One may increase $\eta$ by decreasing $|Q|$, as $|W|$ falls faster, but extending this concept to a heat pump without compromising cooling power would incur the prohibitive technological challenges of high-frequency operation.

Materials efficiency $\eta$ may be used to compare caloric materials for similar values of $|Q|$, and these depend on both the method of normalization and the change in driving field ${ }^{80}$. It has been reported that the $\mathrm{mC}$ alloy Ni-Ti shows ${ }^{110} \eta \sim 13$ when $|Q| \sim 16 \mathrm{~J} \mathrm{~cm}^{-3}$ is developed by $\left|\Delta \sigma_{\mathrm{u}}\right| \sim 30 \mathrm{MPa}$, and it has been reported that EC ceramic and polymer films show ${ }^{80}$ efficiencies in the range $\eta \sim 3-8$ when $|Q| \sim 30 \mathrm{~J} \mathrm{~cm}^{-3}$ is developed by $|\Delta E| \sim 1000 \mathrm{kV} \mathrm{cm}{ }^{-1}$. It remains to establish efficiency values for MC materials, and compare all three types of caloric materials in this way (X. Moya, E. Defay, V. Heine and N. D. Mathur, Commentary in preparation for Nature Physics).

\section{Magnetocaloric cooling}

MC effects are still exploited to reach ultra-low temperatures in research laboratories, and have been suggested for the liquefaction of nitrogen gas and helium gas. The focus on MC cooling near room temperature has led to over 40 prototype cooling devices ${ }^{55}$, e.g. 
using an active magnetic regenerator to pump $51 \mathrm{~W}$ with $T_{\text {sink }}-T_{\text {load }} \sim 18 \mathrm{~K}$, or $9 \mathrm{~W}$ with $T_{\text {sink }}-T_{\text {load }} \sim 40 \mathrm{~K}$ (ref. 111). This performance was achieved by driving relatively small MC effects in Gd particles using $\mu_{0}|\Delta H|=1.5 \mathrm{~T}$ from permanent magnets, but efficiency was not discussed. By contrast, $\mu_{0}|\Delta H|=7 \mathrm{~T}$ was used to drive the Gd plates in the nominally unloaded prototype of Brown ${ }^{105}$ where $T_{\mathrm{h}}-T_{\mathrm{c}}=80 \mathrm{~K}$. Achieving this larger field change with an electromagnet was challenging, and would normally require relative motion with respect to a superconducting magnet.

The values of $T_{\text {sink }}-T_{\text {load }}$ that can be achieved in lightly loaded prototype MC heat pumps $^{55}$ are comparable with the value of $T_{\mathrm{h}}-T_{\mathrm{c}} \sim 49 \mathrm{~K}$ that is required for chilled refrigeration between $T_{\text {load }}=3{ }^{\circ} \mathrm{C}$ and $T_{\text {sink }}=32{ }^{\circ} \mathrm{C}$, assuming that heat flow is driven in domestic refrigerators by setting both $T_{\mathrm{c}}-T_{\text {load }}$ and $T_{\text {sink }}-T_{\mathrm{h}}$ to $10 \mathrm{~K}$ (a freezer with $T_{\text {load }}=-18{ }^{\circ} \mathrm{C}$ would require $\left.T_{\mathrm{h}}-T_{\mathrm{c}} \sim 70 \mathrm{~K}\right)$. However, energy efficient $\mathrm{MC}$ cooling is not established for these useful values of $T_{\mathrm{h}}-T_{\mathrm{c}}$. The most highly cited report ${ }^{112}$ of an MC refrigerator prototype infers an efficiency of $\sim 40 \%$ for $T_{\text {sink }}-T_{\text {load }} \sim 10 \mathrm{~K}$, falling to $\sim 20 \%$ for $T_{\text {sink }}-T_{\text {load }} \sim 20 \mathrm{~K}$. These efficiencies, obtained at limited values of $T_{\text {sink }}-T_{\text {load }}$, fall short of the putative $60 \%$ efficiency for vapour-compression refrigerators. A $60 \%$ efficiency, erroneously quoted elsewhere for the fridge in question, has yet to be demonstrated.

\section{Electrocaloric cooling}

The first EC refrigerator prototype ${ }^{113}$ was developed in the former USSR, in effect reinventing the regenerator concept by cycling liquid pentane over two sets of 
$0.3 \mathrm{~mm}$-thick $\mathrm{PbSc}_{0.5} \mathrm{Ta}_{0.5} \mathrm{O}_{3}$ plates that were electrically driven in antiphase. The largest value of $T_{\mathrm{h}}-T_{\mathrm{c}} \sim 5 \mathrm{~K}$ in the nominally unloaded prototype was achieved using $|\Delta E| \sim 60 \mathrm{kV} \mathrm{cm}^{-1}$ to drive a non-adiabatic temperature change of $0.9 \mathrm{~K}$ in each plate. (Removing the regenerator fluid yielded nominally adiabatic conditions, permitting a higher value of $|\Delta T| \sim 1.4 \mathrm{~K}$ in the plates, despite the reduction of $|\Delta E| \sim 30 \mathrm{kV} \mathrm{cm}{ }^{-1}$ imposed by the reduced breakdown field.) Gaseous helium at $1 \mathrm{MPa}$ proved to be an ineffective regenerator, as only $T_{\mathrm{h}}-T_{\mathrm{c}} \sim 1.8 \mathrm{~K}$ could be achieved with $|\Delta E| \sim 26 \mathrm{kV} \mathrm{cm}^{-1}$.

Recent publications have demonstrated sustained EC cooling using cyclical mechanical motion, with the EC working body itself as the regenerator ${ }^{114}$ (cf. AMR) ${ }^{22}$, or with a solid regenerator possessing anisotropic thermal conductivity ${ }^{115}$. In both cases, MLCs formed the working EC bodies, as their interdigitated metallic electrodes provide good thermal access to a macroscopic assembly of EC films ${ }^{52,63}$. It seems likely that any future applications will be based on MLCs, as they simultaneously overcome all of the disadvantages associated with bulk and film: bulk EC materials show small values of $|\Delta T|$ and low thermal conductivities; whereas EC films pump little heat and tend to come with substrates that constitute thermal anchors. However, existing MLCs mass-produced as electronic components show serendipitous EC effects ${ }^{52}$ of just $|\Delta T| \sim 0.5 \mathrm{~K}$. If the layers of doped $\mathrm{BaTiO}_{3}$ were replaced with better EC materials, and if the $\mathrm{Ni}$ electrodes were replaced with copper or silver to increase thermal conductivity by a factor of four, then predictions from a lumped thermal model indicate that a $1 \mathrm{~m}^{2}$ sheet of MLCs could pump $40 \mathrm{~kW}$ via both sets of thermally parallel terminals ${ }^{63}$. A subsequent finite-element analysis has revealed that substantially larger cooling powers may be achieved by 
optimizing MLC geometry ${ }^{116}$. If MLC fabrication could also be optimised, then EC cooling could have a bright future.

\section{Mechanocaloric cooling}

Sustained mC cooling was recently demonstrated using NiTi wires under cyclical tensile stress (Ichiro Takeuchi and Jun Cui, private communication). These wires were cyclically connected to a load and a sink via regenerators that comprised mobile reservoirs of aqueous ethanol. The device COP was unity while pumping $15 \mathrm{~W}$, but significant heat leaks limited $T_{\text {sink }}-T_{\text {load }}$ to $2 \mathrm{~K}$. The oldest known caloric effect was thus the last to be exploited in a cooling device, with plenty of scope for improvement.

\section{Outlook}

All three caloric effects were originally reported in the order that their giant counterparts were much later reported. All three caloric effects have now been demonstrated in conventional and inverse form. All three caloric effects have now been studied in bulk samples and films. And all three caloric effects have now been exploited to demonstrate heat-pump prototypes. Here we will discuss the intrinsic merits and demerits of the three competing caloric effects, possible developments in caloric materials, and possible developments in heat-pump design.

Let us compare the three caloric effects in terms of (1) materials cost, (2) propensity to breakdown, (3) ease of field application, and (4) irreversible field-driven heating. (1) MC compounds that do not contain expensive elements are included in current efforts to scale 
up materials production. EC ceramics and polymers, along with $\mathrm{mC}$ alloys, tend to comprise relatively cheap materials components. (2) A magnetic field might only promote breakdown indirectly via magnetostriction, but electrical breakdown normally limits $\mathrm{EC}$ effects, and $\mathrm{mC}$ materials under tensile stress are prone to plastic deformation followed by mechanical breakdown. (3) The need to generate several tesla in order to fully drive transitions in giant MC materials is not compatible with the use of (expensive) permanent magnets and typical electromagnets. However, electric fields are so easy to generate that the likely need for hardwired electrodes seems a small price to pay, and stress fields could be electrically generated using actuators or motors. (4) Eddy-current heating due to a changing magnetic field could limit operating frequency and thus cooling power, Joule heating could limit applied electric-field strength, and frictional heating could compromise $\mathrm{mC}$ performance.

One factor that could decisively favour EC cooling over MC and $\mathrm{mC}$ cooling is energy recovery. This is because at least $80 \%$ of the unused electrical work done on capacitors may be readily recovered for subsequent cycles using electronic circuitry (manuscript in preparation, E. Defay, G. Despesse, S. Crossley, X. Moya and N. D. Mathur). One factor that is not likely to determine the relative potential of the three competing caloric materials is thermal conductivity. Even metallic $\mathrm{MC}$ and $\mathrm{mC}$ materials possess rather low values, hence the need to permeate subdivided caloric material using mobile fluids ${ }^{12}$, metallic phases ${ }^{62}$ or metallic layers ${ }^{52,63}$, as mentioned earlier. 
The primary challenge in the development of caloric materials is to increase the values of $|\Delta T|$ and $|Q|$ that may be reliably achieved, whatever the application. One should also seek to reduce the magnitude of the driving field. In these ways, it is possible to increase materials efficiency $\eta$, and thus ultimately the COP for any resulting heat pump. However, in order to reversibly drive the large caloric effects associated with hysteretic first-order transitions, at temperatures well away from the coexistence regime, it is necessary for the applied field to exceed some threshold value (except when driving extrinsic $\mathrm{MC}$ effects ${ }^{102}$ ). By contrast, no threshold field is required when driving anhysteretic second-order transitions over a wide range of temperatures. Moreover, second-order transitions may in practice possess only a small peak in heat capacity such that $|\Delta T|$ is not unduly compromised. However, first-order transitions tend to show large heats of transition. Therefore it may prove optimal to operate at the crossover between first and second-order transitions. This could be achieved via strain engineering for EC films ${ }^{15,80}$, and via composition-spread techniques as demonstrated for $\mathrm{mC}$ and $\mathrm{MC}$ materials ${ }^{88,117}$. Alternatively, one might further explore disordered systems with broad phase transitions, namely spin glasses, relaxor ferroelectrics and strain glasses. EC effects in relaxors (denoted (r) in Table 2) have already attracted quite some attention.

There are many challenges in the development of heat pump design that lie well beyond the scope of this article. Applications will likely require heat switches or thermal diodes, but an alternative strategy using an asymmetric sequence of field pulses has been suggested ${ }^{118}$. Heat switches could comprise Peltier units ${ }^{107}$, liquid crystals in which convection $^{119}$ or reorientation ${ }^{120}$ are electrically controlled, actuators exploiting 
field-driven distortions such as those arising in caloric materials themselves, or superconductors for low-temperature applications ${ }^{11}$. Thermal diodes such as heat pipes ${ }^{108}$ require no active control and could therefore prove more attractive than heat switches. Heat pipes are well established tools in thermal management, and operate on the principle that a fluid evaporates at one end when absorbing heat, subsequently condenses at the other end on losing heat, and then trickles back to the hot end due to gravity or capillarity. Solid-state thermal diodes have also been demonstrated ${ }^{121,122}$, but performance remains unconvincing.

Magnetically driven irreversible heating near room temperature has been exploited for induction cooking and other applications, but it remains to be seen whether reversible caloric effects associated with phase transitions will be exploited in technologically useful devices. There is in any case plenty of scope for interesting science, e.g. the development of microscopic theories for the different types of EC materials, investigations of inhomogeneity using modern imaging methods, and studies of caloric effects in materials that might display ferrotoroidic order of a magnetic or electrical nature $^{123}$. Some of the new science will encroach on other fields of research, e.g. thermally mediated magnetoelectric coupling ${ }^{124}$, or hitherto unexplored EC effects in ferromagnetic semiconductors away from the Curie temperature ${ }^{125}$. It should therefore prove instructive to explore cross-fertilization between the three caloric effects, and how these caloric phenomena interface with other areas of research. 


\section{Acknowledgements}

For information about refrigerator performance, we thank I. Wood (Adande Refrigeration), and M. Tomlin and P. Roberts (Sharp Laboratories of Europe). For discussions, we thank M. Bibes, G. V. Brown, S. Crossley, E. Defay, S. Fähler, Z. Kutnjak, Ll. Mañosa, A. Planes, N. Pryds, J. F. Scott, V. Shvartsman and K. Uchino. X. M. is grateful for support from the Herchel Smith Fund, the Spanish MEC Ramón y Cajal programme, and the Royal Society. S. K. N. is grateful for support from the Royal Society.

\section{Competing financial interests}

The authors declare no competing financial interests.

Corresponding author: ndm12@cam.ac.uk (N. D. M.). 


\section{References}

[1] Gough, J. A description of a Property of Caoutchouc or Indian Rubber; with some Reflections on the Cause of the Elasticity of this Substance. Memoirs of the Literary and Philosophical Society of Manchester 1 (2nd Series), 288-295 (1805).

[2] Joule, J. P. On some Thermo-dynamic Properties of Solids. Phil. Trans. 149, 91-131 (1859).

[3] Thomson, W. On the Thermoelastic and Thermomagnetic Properties of Matter, Part I. Quarterly Journal of Mathematics, April 1855.

[4] Thomson, W. On the Thermoelastic, Thermomagnetic, and Pyroelectric Properties of Matter. The London, Edinburgh and Dublin Philosophical Magazine and Journal of Science 5, 4-27 (1878). Includes a reprint of ref. 3 on eC work, a reprint of MC work from 1860, and new EC work.

[5] Smith, A. Who discovered the magnetocaloric effect? Eur. Phys. J. H 38, 507-517 (2013).

[6] Warburg, E. Magnetische Untersuchungen über einige Wirkungen der Koerzitivkraft. Ann. Phys. 13, 141-164 (1881).

[7] Weiss, P. and Piccard, A. Le phénomène magnétocalorique. J. Phys. Theor. Appl. 7, 103-109 (1917).

[8] Kobeko, P. and Kurtschatov, J. Dielektrische Eigenschaften der Seignettesalzkristalle. Z. Phys. 66, 192-205 (1930).

[9] Giauque, W. F. and MacDougall, D. P. Attainment of Temperatures Below $1^{\circ}$ Absolute by Demagnetization of $\mathrm{Gd}_{2}\left(\mathrm{SO}_{4}\right)_{3} \cdot 8 \mathrm{H}_{2} \mathrm{O}$. Phys. Rev. 43, 768 (1933).

[10] Collins, S. C. and Zimmerman, F. J. Cyclic Adiabatic Demagnetization. Phys. Rev. 90, 991-992 (1953).

[11] Heer, C. V., Barnes, C. B. and Daunt, J. G. The Design and Operation of a Magnetic Refrigerator for Maintaining Temperatures below $1^{\circ} \mathrm{K}$. Rev. Sci. Instrum. 25, 1088-1098 (1954).

[12] Brown, G. V. Magnetic heat pumping near room temperature. J. Appl. Phys. 47, 3673-3680 (1976).

[13] Rodríguez, C. and Brown, L. C. The Thermal Effect Due to Stress-Induced Martensite Formation in $\beta$-CuAlNi Single Crystals. Metall. Trans. A 11, 147-150 (1980). 
[14] Nikitin, S. A., Myalikgulyev, G., Tishin, A. M., Annaorazov, M. P., Asatryan, K. A. and Tyurin, A. L. The magnetocaloric effect in $\mathrm{Fe}_{49} \mathrm{Rh}_{51}$ compound. Phys. Lett. A. 148, 363-366 (1990).

[15] Mischenko, A. S., Zhang, Q., Scott, J. F., Whatmore, R. W. and Mathur, N. D. Giant Electrocaloric Effect in Thin-Film $\mathrm{PbZr}_{0.95} \mathrm{Ti}_{0.05} \mathrm{O}_{3}$. Science 311, 1270-1271 (2006).

[16] Neese, B., Chu, B., Lu, S.-G., Wang, Y., Furman, E. and Zhang, Q. M. Large Electrocaloric Effect in Ferroelectric Polymers Near Room Temperature. Science 321, 821-823 (2008).

[17] Pecharsky, V. K. and Gschneidner Jr., K. A. Giant Magnetocaloric Effect in $\mathrm{Gd}_{5} \mathrm{Si}_{2} \mathrm{Ge}_{2}$. Phys. Rev. Lett. 78, 4494-4497 (1997).

[18] de Oliveira, N. A. Entropy change upon magnetic field and pressure variations. Appl. Phys. Lett. 90, 052501 (2007).

[19] Bonnot, E., Romero, R., Mañosa, Ll., Vives, E. and Planes, A. Elastocaloric Effect Associated with the Martensitic Transition in Shape-Memory Alloys.

Phys. Rev. Lett. 100, 125901 (2008).

[20] Mañosa, Ll., González-Alonso, D., Planes, A., Bonnot, E., Barrio, M., Tamarit, J.-Ll., Aksoy, S. and Acet, M. Giant solid-state barocaloric effect in the Ni-Mn-In magnetic shape-memory alloy. Nat. Mater. 9, 478-481 (2010).

[21] Fähler, S., Rößler, U. K., Kastner, O., Eckert, J., Eggeler, G., Emmerich, H., Entel, P., Müller, S., Quandt, E. and Albe, K. Caloric Effects in Ferroic Materials: New Concepts for Cooling. Adv. Eng. Mater. 14, 10-19 (2012).

[22] Pecharsky, V. K. and Gschneidner Jr., K. A. Magnetocaloric effect and magnetic refrigeration. J. Magn. Magn. Mater. 200, 44-56 (1999).

[23] Gschneidner K. A., Pecharsky V. K., Tsokol A. O. Recent developments in magnetocaloric materials. Rep. Prog. Phys. 68, 1479-1539 (2005).

[24] Bruck, E. Developments in magnetocaloric refrigeration. J. Phys. D: Appl. Phys. 38, R381-R391 (2005).

[25] Franco, V., Blazquez, J. S., Ingale, B. and Conde, A. The Magnetocaloric Effect and Magnetic Refrigeration Near Room Temperature: Materials and Models.

Annu. Rev. Mater. Res. 42, 305-342 (2012).

[26] Smith, A., Bahl, C. R. H., Christian R. H., Bjork, R., Engelbrecht, K. and Nielsen, K. K. Materials Challenges for High Performance Magnetocaloric Refrigeration Devices. Adv. Energy Mater. 2, 1288 -1318 (2012). 
[27] Correia, T. and Zhang, Q. Electrocaloric Materials (Springer, 2014).

[28] Lu, S. G. and Zhang, Q. Electrocaloric Materials for Solid-State Refrigeration. Adv. Mater. 21, 1983-1987 (2009).

[29] Scott, J. F. Electrocaloric Materials. Annu. Rev. Mater. Res. 41, 229-240 (2011).

[30] Valant, M. Electrocaloric materials for future solid-state refrigeration technologies. Prog. Mater. Sci. 57, 980-1009 (2012).

[31] Yuce, S., Barrio, M., Emre, B., Stern-Taulats, E., Planes, A., Tamarit, J.-Ll., Mudryk, Y., Gschneidner Jr., K. A., Pecharsky, V. K. and Mañosa, Ll. Barocaloric effect in the magnetocaloric prototype $\mathrm{Gd}_{5} \mathrm{Si}_{2} \mathrm{Ge}_{2}$. Appl. Phys. Lett. 101, 071906 (2012).

[32] Mañosa, Ll., González-Alonso, D., Planes, A., Barrio, M., Tamarit, J.-Ll., Titov, I. S., Acet, M., Bhattacharyya, A. and Majumdar, S. Inverse barocaloric effect in the giant magnetocaloric La-Fe-Si-Co compound. Nat. Commun. 2, 595 (2011).

[33] Müller, K. A., Fauth, F., Fischer, S., Koch, M., Furrer, A. and Lacorre, Ph. Cooling by adiabatic pressure application in $\mathrm{Pr}_{1-\mathrm{x}} \mathrm{La}_{\mathrm{x}} \mathrm{NiO}_{3}$. Appl. Phys. Lett. 73, 1056-1058 (1998).

[34] Strässle, T., Furrer, A., Hossain, Z. and Geibel, C. Magnetic cooling by the application of external pressure in rare-earth compounds. Phys. Rev. B 67, 054407 (2003).

[35] Brown, L. C. The Thermal Effect in Pseudoelastic Single Crystals of $\beta-\mathrm{CuZnSn}$. Metall. Trans. A 12, 1491-1494 (1981).

[36] Cui, J., Wu, Y., Muehlbauer, J., Hwang, Y., Radermacher, R., Fackler, S., Wuttig, M. and Takeuchi, I. Demonstration of high efficiency elastocaloric cooling with large $\Delta$ T using NiTi wires. Appl. Phys. Lett. 101, 073904 (2012).

[37] Shaw, J. A. and Kyriakides, S. Thermomechanical aspects of NiTi. J. Mech. Phys. Solids 43, 1243-1281 (1995).

[38] Pieczyska, E. A., Gadaj, S. P., Nowacki, W. K. and Tobushi, H. Phase-Transformation Fronts Evolution for Stress- and Strain-Controlled Tension Tests in TiNi Shape Memory Alloy. Exp. Mech. 46, 531-542 (2006).

[39] Bechtold, C., Chluba, C., Lima de Miranda, R. and Quandt, E. High cyclic stability of the elastocaloric effect in sputtered TiNiCu shape memory films. Appl. Phys. Lett. 101, 091903 (2012). 
[40] Soto-Parra, D. E., Vives, E., Gonzalez-Alonso, D., Mañosa, Ll., Planes, A., Romero, R., Matutes-Aquino, J. A., Ochoa-Gamboa, R. A. and Flores-Zuniga, H. Stress- and magnetic field-induced entropy changes in Fe-doped Ni-Mn-Ga shape-memory alloys. Appl. Phys. Lett. 96, 071912 (2010).

[41] Levitin, R. Z., Snegirev, V. V., Kopylov, A. V., Lagutin, A. S. and Gerber, A. Magnetic method of magnetocaloric effect determination in high pulsed magnetic fields. J. Magn. Magn. Mater. 170, 223-227 (1997).

[42] Dan'kov, S. Y., Tishin, A. M., Pecharsky, V. K. and Gschneidner Jr, K. A. Magnetic phase transitions and the magnetothermal properties of gadolinium. Phys. Rev. B 57, 3478-3490 (1998).

[43] Casanova, F. Labarta, A., Batlle, A., Pérez-Reche, F. J., Vives, E., Mañosa, Ll. and Planes, A. Direct observation of the magnetic-field-induced entropy change in $\mathrm{Gd}_{5}\left(\mathrm{Si}_{x} \mathrm{Ge}_{1-x}\right)_{4}$ giant magnetocaloric alloys. Appl. Phys. Lett. 86, 262504 (2005).

[44] Moya, X., Mañosa, Ll., Planes, A., Krenke, T., Duman, E., Acet, M. and Wassermann, E.F. Calorimetric study of the inverse magnetocaloric effect in ferromagnetic Ni-Mn-Sn. J. Magn. Magn. Mater. 316, e572-e574 (2007).

[45] Christensen, D. V., Bjørk, R., Nielsen, K. K., Bahl, C. R. H., Smith, A. and Clausen, S. Spatially resolved measurements of the magnetocaloric effect and the local magnetic field using thermography. J. Appl. Phys. 108, 063913 (2010).

[46] Thacher, P. D. Electrocaloric Effects in Some Ferroelectric and Antiferroelectric $\mathrm{Pb}(\mathrm{Zr}, \mathrm{Ti}) \mathrm{O}_{3}$ Compounds. J. Appl. Phys. 39, 1996-2002 (1968).

[47] Tuttle, B. A. and Payne, D. A. The effects of microstructure on the electrocaloric properties of $\mathrm{Pb}(\mathrm{Zr}, \mathrm{Sn}, \mathrm{Ti}) \mathrm{O}_{3}$ ceramics. Ferroelectrics 37, 603-606 (1981).

[48] Wiseman, G. G. and Kuebler, J. K. Electrocaloric Effect in Ferroelectric Rochelle Salt. Phys. Rev. 131, 2023- 2027 (1963).

[49] Moya, X., Stern-Taulats, E., Crossley, S., González-Alonso, D., Kar-Narayan, S., Planes, A., Mañosa, Ll. and Mathur, N. D. Giant Electrocaloric Strength in Single-Crystal $\mathrm{BaTiO}_{3}$. Adv. Mater. 25, 1360-1365 (2013).

[50] Lu, S. G., Rožič, B., Zhang, Q. M., Kutnjak, Z. and Neese, B. Enhanced electrocaloric effect in ferroelectric poly(vinylidene-fluoride/trifluoroethylene) 55/45 mol \% copolymer at ferroelectric-paraelectric transition. Appl. Phys. Lett. 98, 122906 (2011).

[51] Lu, S. G., Rožič, B., Zhang, Q. M., Kutnjak, Z., Pirc, R., Lin, M., Li, X. and Gorny, L. Comparison of directly and indirectly measured electrocaloric effect in relaxor ferroelectric polymers. Appl. Phys. Lett. 97, 202901 (2010). 
[52] Kar-Narayan, S. and Mathur, N. D. Direct and indirect electrocaloric measurements using multilayer capacitors. J. Phys. D: Appl. Phys. 43, 032002 (2010).

[53] Kar-Narayan, S., Crossley, S., Moya, X., Kovacova, V., Abergel, J., Bontempi, A., Baier, N., Defay, E. and Mathur, N. D. Direct electrocaloric measurements of a multilayer capacitor using scanning thermal microscopy and infra-red imaging. Appl. Phys. Lett. 102, 032903 (2013).

[54] Tishin, A. M. and Spichkin, Y. I. The Magnetocaloric Effect and its Applications (Institute of Physics, 2003).

[55] Yu, B., Liu, M., Egolf, P. W. and Kitanovski, A. A review of magnetic refrigerator and heat pump prototypes built before the year 2010. Int. J. Refrig. 33, 1029-1060 (2010).

[56] Annaorazov, M. P., Nikitin, S. A., Tyurin, A. L., Asatryan, K. A. and Dovletov, A. Kh. Anomalously high entropy change in FeRh alloy. J. Appl. Phys. 79, 1689-1695 (1996).

[57] Nikitin, S. A., Myalikgulyev, G., Annaorazov, M. P., Tyurin, A. L., Myndyev, R. W. and Akopyan, S. A. Giant elastocaloric effect in FeRh alloy. Phys. Lett. A 171, 234-236 (1992).

[58] Dung, N. H., Ou, Z. Q., Caron, L., Zhang, L., Cam Thanh, D. T., de Wijs, G. A., de Groot, R. A., Buschow, K. H. J. and Brück, E. Mixed Magnetism for Refrigeration and Energy Conversion. Adv. Energy Mater. 1, 1215-1219 (2011).

[59] Zhang, Q., Thota, S., Guillou, F., Padhan, P., Hardy, V., Wahl, A. and Prellier, W. Magnetocaloric effect and improved relative cooling power in $\left(\mathrm{La}_{0.7} \mathrm{Sr}_{0.3} \mathrm{MnO}_{3} / \mathrm{SrRuO}_{3}\right)$ superlattices. J. Phys.: Condens. Matter 23, 052201 (2011).

[60] Balli, M., Fruchart, D. and Gignoux, D. Optimization of La(Fe, Co ${ }_{13-x} \mathrm{Si}_{x}$ based compounds for magnetic refrigeration. J. Phys.: Condens. Matter 19, 236230 (2007).

[61] Morrison, K., Barcza, A., Moore, J. D., Sandeman, K. G., Chattopadhyay, M. K., Roy, S. B., Caplin, A. D. and Cohen, L. F. The magnetocaloric performance in pure and mixed magnetic phase CoMnSi. J. Phys. D: Appl. Phys. 43, 195001 (2010).

[62] Lyubina, J., Hannemann, U., Cohen, L. F. and Ryan, M. P. Novel La(Fe,Si) ${ }_{13} / \mathrm{Cu}$ Composites for Magnetic Cooling. Adv. Energy Mater. 2, 1323-1327 (2012).

[63] Kar-Narayan, S. and Mathur, N. D. Predicted cooling powers for multilayer capacitors based on various electrocaloric and electrode materials. Appl. Phys. Lett. 95, 242903 (2009). 
[64] Lyubina, J., Schäfer, R., Martin, N., Schultz, L. and Gutfleisch, O. Novel Design of $\mathrm{La}(\mathrm{Fe}, \mathrm{Si})_{13}$ Alloys Towards High Magnetic Refrigeration Performance. Adv. Mater. 22, 3735-3739 (2010).

[65] Moore, J. D., Morrison, K., Sandeman, K. G., Katter, M., and Cohen, L. F. Reducing extrinsic hysteresis in first-order $\mathrm{La}(\mathrm{Fe}, \mathrm{Co}, \mathrm{Si})_{13}$ magnetocaloric systems. Appl. Phys. Lett. 95, 252504 (2009).

[66] Provenzano, V., Shapiro, A. J. and Shull, R. D. Reduction of hysteresis losses in the magnetic refrigerant $\mathrm{Gd}_{5} \mathrm{Ge}_{2} \mathrm{Si}_{2}$ by the addition of iron. Nature 429, 853-857 (2004).

[67] Fujita, A., Fujieda, S., Hasegawa, Y., and Fukamichi, K. Itinerant-electron metamagnetic transition and large magnetocaloric effects in $\mathrm{La}\left(\mathrm{Fe}_{x} \mathrm{Si}_{1-x}\right)_{13}$ compounds and their hydrides. Phys. Rev. B 67, 104416 (2003).

[68] Pareti, L., Solzi, M., Albertini, F., Paoluzi, A. Giant entropy change at the co-occurrence of structural and magnetic transitions in the $\mathrm{Ni}_{2.19} \mathrm{Mn}_{0.81} \mathrm{Ga}$ Heusler alloy. Eur. Phys. J. B 32, 303-307 (2003).

[69] Dalal, N. S., Klymachyov, A. and Bussmann-Holder, A. Coexistence of Order-Disorder and Displacive Features at the Phase Transitions in HydrogenBonded Solids: Squaric Acid and its Analogs. Phys. Rev. Lett. 81, 5924-5927 (1998).

[70] Zalar, B., Laguta, V. V. and Blinc, R. NMR Evidence for the Coexistence of Order-Disorder and Displacive Components in Barium Titanate. Phys. Rev. Lett. 90, 037601 (2003).

[71] von Baumgartner, H. Elektrische Sättigungserscheinungen und elektrokalorischer Effekt von Kaliumphosphat $\mathrm{KH}_{2} \mathrm{PO}_{4}$. Helv. Phys. Acta 23, 651-696 (1950).

[72] Strukov, B.A. Electrocaloric effect in single-crystal triglycine sulfate. Sov. Phys. Crystallogr. 11, 757-759 (1967).

[73] Kikuchi, A. and Sawaguchi, E. Electrocaloric Effect in $\mathrm{SrTiO}_{3}$. J. Phys. Soc. Jpn 19, 1497-1498 (1964).

[74] Lombardo, G. and Pohl, R. O. Electrocaloric Effect and a New Type of Impurity Mode. Phys. Rev. Lett. 15, 291-293 (1965).

[75] Shepherd, I. and Fehrer, G. Cooling by Adiabatic Depolarization of $\mathrm{OH}^{-}$Molecules in KCl. Phys. Rev. Lett. 15, 194-198 (1965).

[76] Karchevskii, A. I. Electrocaloric effect in polycrystalline barium titanate. Fiz. Tverd. Tela+ 3, 2249-2254 (1962). 
[77] Sinyavsky, Y. V., Pashkov, N. D., Gorovoy, Y. M., Lugansky, G. E. and Shebanov, L. The optical ferroelectric ceramic as working body for electrocaloric refrigeration. Ferroelectrics 90, 213-217(1989).

[78] Shebanov, L. and Borman, K. On lead-scandium tantalate solid solutions with high electrocaloric effect. Ferroelectrics 127, 143-148 (1992).

[79] Liu, X. Q., Chen, T. T., Wu, Y. J. and Chen, X. M. Enhanced Electrocaloric Effects in Spark Plasma-Sintered $\mathrm{Ba}_{0.65} \mathrm{Sr}_{0.35} \mathrm{TiO}_{3}$-Based Ceramics at Room Temperature. J. Am. Ceram. Soc. 96, 1021-1023 (2013).

[80] Defay, E., Crossley, S., Kar-Narayan, S., Moya, X. and Mathur, N. D. The electrocaloric efficiency of ceramic and polymer films. Adv. Mater. 25, 3337-3342 (2013).

[81] Rozic, B., Ursic, H., Holc, J., Kosec, M. and Kutnjak, Z. Direct Measurements of the Electrocaloric Effect In Substrate-Free PMN-0.35PT Thick Films on a Platinum Layer. Integr. Ferroelectr. 140, 161-165 (2012).

[82] Rožič, B., Kosec, M., Uršič, H., Holc, J., Malič, B., Zhang, Q. M., Blinc, R., Pirc, R. and Kutnjak, Z. Influence of the critical point on the electrocaloric response of relaxor ferroelectrics. J. Appl. Phys. 110, 064118 (2011).

[83] Pirc, R., Kutnjak, Z., Blinc, R. and Zhang, Q. M. Upper bounds on the electrocaloric effect in polar solids. Appl. Phys. Lett. 98, 021909 (2011).

[84] Peräntie, J., Hagberg, J., Uusimäki, A. and Jantunen, H. Electric-field-induced dielectric and temperature changes in a $<011>$-oriented $\mathrm{Pb}\left(\mathrm{Mg}_{1 / 3} \mathrm{Nb}_{2 / 3}\right) \mathrm{O}_{3}-\mathrm{PbTiO}_{3}$ single crystal. Phys. Rev. B 82, 134119 (2010).

[85] Strässle, T., Furrer, A. and Müller, K. A. Cooling by adiabatic application of pressure - the barocaloric effect. Physica B 276-278, 944-945 (2000).

[86] Xiao, F., Fukuda, T. and Kakeshita, T. Significant elastocaloric in a Fe-31.2Pd (at. \%) single crystal. Appl. Phys. Lett. 102, 161914 (2013).

[87] Gorev, M. V., Bogdanov, E. V., Flerov, I. N., Kocharova, A. G. and Laptash, N. M. Investigation of Thermal Expansion, Phase Diagrams, and Barocaloric Effect in the $\left(\mathrm{NH}_{4}\right)_{2} \mathrm{WO}_{2} \mathrm{~F}_{4}$ and $\left(\mathrm{NH}_{4}\right)_{2} \mathrm{MoO}_{2} \mathrm{~F}_{4}$ Oxyfluorides. Phys. Solid State+ 52, 167-175 (2010).

[88] Zarnetta, R., Takahashi, R., Young, M. L., Savan, A., Furuya, Y., Thienhaus, S., Maaß, B., Rahim, M., Frenzel, J., Brunken, H., Chu, Y. S., Srivastava, V., James, R. D., Takeuchi, I., Eggeler, G. and Ludwig, A. Identification of Quaternary Shape Memory Alloys with Near-Zero Thermal Hysteresis and Unprecedented Functional Stability. Adv. Funct. Mater. 20, 1917-1923 (2010). 
[89] Rodriguez, E. L. and Filisko, F. E. Thermoelastic temperature changes in poly(methyl methacrylate) at high hydrostatic pressure: Experimental. J. Appl. Phys. 53, 6536 (1982).

[90] Sun, Y., Kamarad, J., Arnold, Z., Kou, Z.-Q. and Cheng, Z.-H. Tuning of magnetocaloric effect in a $\mathrm{La}_{0.69} \mathrm{Ca}_{0.31} \mathrm{MnO}_{3}$ single crystal by pressure. Appl. Phys. Lett. 88, 102505 (2006).

[91] Albertini, F., Kamarad, J., Arnold, Z., Pareti, L., Villa, E. and Righi, L. Pressure effects on the magnetocaloric properties of Ni-rich and $\mathrm{Mn}$-rich $\mathrm{Ni}_{2} \mathrm{MnGa}$ alloys. J. Magn. Magn. Mater. 316, 364-367 (2007).

[92] Lyubina, J., Nenkov, K., Schultz, L. and Gutfleisch, O. Multiple Metamagnetic Transitions in the Magnetic Refrigerant $\mathrm{La}(\mathrm{Fe}, \mathrm{Si})_{13} \mathrm{H}_{x}$. Phys. Rev. Lett. 101, 177203 (2008).

[93] Liu, J., Gottschall, T., Skokov, K. P., Moore, J. D. and Gutfleisch, O. Giant magnetocaloric effect driven by structural transitions. Nat. Mater. 11, 620-626 (2012).

[94] Morellon, L., Arnold, Z., Magen, C., Ritter, C., Prokhnenko, O., Skorokhod, Y., Algarabel, P. A., Ibarra, M. R. and Kamarad, J. Pressure Enhancement of the Giant Magnetocaloric Effect in $\mathrm{Tb}_{5} \mathrm{Si}_{2} \mathrm{Ge}_{2}$. Phys. Rev. Lett. 93, 137201 (2004).

[95] Samara, G. A. Pressure and temperature dependence of the dielectric properties and phase transitions of the ferroelectric perovskites: $\mathrm{PbTiO}_{3}$ and $\mathrm{BaTiO}_{3}$. Ferroelectrics 2, 277-289 (1971).

[96] Pertsev, N. A., Zembilgotov, A. G. and Tagantsev, A. K. Effect of Mechanical Boundary Conditions on Phase Diagrams of Epitaxial Ferroelectric Thin Films. Phys. Rev. Lett. 80, 1988-1991 (1998).

[97] Akcay, G., Alpay, S. P., Rossetti Jr., G. A. and Scott, J. F. Influence of mechanical boundary conditions on the electrocaloric properties of ferroelectric thin films. J. Appl. Phys. 103, 024104 (2008).

[98] Qiu, J. H. and Jiang, Q. Misfit strain dependence of electrocaloric effect in epitaxial $\mathrm{Pb}\left(\mathrm{Zr}_{1-x} \mathrm{Ti}_{x}\right) \mathrm{O}_{3}$ thin films. J. Appl. Phys. 103, 084105 (2008).

[99] Liu, Z. K., Li, X. and Zhang, Q. M. Maximizing the number of coexisting phases near invariant critical points for giant electrocaloric and electromechanical responses in ferroelectrics. Appl. Phys. Lett. 101, 082904 (2012). 
[100] Haeni, J. H., Irvin, P., Chang, W., Uecker, R., Reiche, P., Li, Y. L., Choudhury, S., Tian, W., Hawley, M. E., Craigo, B., Tagantsev, A. K., Pan, X. Q., Streiffer, S. K., Chen, L. Q., Kirchoefer, S. W., Levy, J. and Schlom, D. G. Room-temperature ferroelectricity in strained $\mathrm{SrTiO}_{3}$. Nature 430, 758-761 (2004).

[101] Mosca, D. H., Vidal, F. and Etgens, V. H. Strain Engineering of the Magnetocaloric Effect in MnAs Epilayers. Phys. Rev. Lett. 101, 125503 (2008).

[102] Moya, X., Hueso, L. E., Maccherozzi, F., Tovstolytkin, A. I., Podyalovskii, D. I., Ducati, C., Phillips, L. C., Ghidini, M., Hovorka, O., Berger, A., Vickers, M. E., Defay, E., Dhesi, S. S. and Mathur, N. D. Giant and reversible extrinsic magnetocaloric effects in $\mathrm{La}_{0.7} \mathrm{Ca}_{0.3} \mathrm{MnO}_{3}$ films due to strain. Nat. Mater. 12, 52-58 (2013).

[103] Sattar, M. A., Saidur, R. and Masjuki, H. H. Performance Investigation of Domestic Refrigerator Using Pure Hydrocarbons and Blends of Hydrocarbons as Refrigerants. World Academy of Science, Engineering and Technology 29, 223-228 (2007).

[104] Wood, M. E. and Potter, W. H. General analysis of magnetic refrigeration and its optimization using a new concept: maximization of refrigerant capacity. Cryogenics 25, 667-683 (1985).

[105] Brown, G. V. and Papell, S. S. Regeneration tests of a room temperature magnetic refrigerator and heat pump. arXiv:1402.3343. Unpublished 1978 manuscript now available online, with permission from G. V. Brown.

[106] Richard, M.-A., Rowe, A. M. and Chahine, R. Magnetic refrigeration: Single and multimaterial active magnetic regenerator experiments. J. Appl. Phys. 95, 2146-2150 (2004).

[107] Mischenko, A. and Mathur, N. Solid State Electrocaloric Cooling Device with Heat Switches and Method of Cooling, GB patent PCT/GB2005/050207 (2005).

[108] Basiulis, A. and Berry, R. L. Solid-state electrocaloric cooling system and method, US patent 4,757,688 (1988).

[109] Annaorazov, M. P., Nikitin, S. A., Tyurin, A. L., Akopyan, S. A. and Myndyev, R. W. Heat pump cycles based on the AF-F transition in Fe-Rh alloys induced by tensile stress. Int. J. Refrig. 25, 1034-1042 (2002).

[110] Quarini, J. and Prince, A. Solid state refrigeration: cooling and refrigeration using crystalline phase changes in metal alloys. Prog. Inst. Mech. Eng., Part C: J. Mech. Eng. Sci. 218, 1175-1178 (2004). 
[111] Yao, G. H., Gong, M. Q. and Wu, J. F. Experimental study on the performance of a room temperature magnetic refrigerator using permanent magnets. Int. J. Refrig. 29, $1267-1273$ (2006)

[112] Zimm, C., Jastrab, A., Sternberg, A., Pecharsky, V. K., Gschneider Jr., K. A., Osborne, M. and Anderson, I. Description and performance of near-room temperature magnetic refrigerator. Adv. Cryog. Eng. 43, 1759-1766 (1998).

[113] Sinyavsky, Y. and Brodyansky, V. M. Experimental testing of electrocaloric cooling with transparent ferroelectric ceramic as working body. Ferroelectrics 131, 321-325 (1992).

[114] Jia, Yanbing and Ju, Y. Sungtaek. A solid-state refrigerator based on the electrocaloric effect. Appl. Phys. Lett. 100, 242901 (2012).

[115] Gu, H., Qian, X., Li, X., Craven, B., Wenyi, Z., Cheng, A., Yao, S. C. and Zhang Q. M. A chip scale electrocaloric effect based cooling device. Appl. Phys. Lett. 102, 122904 (2013).

[116] Crossley, S., McGinnigle, J. R., Kar-Narayan, S. and Mathur, N. D. Finite-element optimisation of electrocaloric multilayer capacitors. Appl. Phys. Lett. 104, 082909 (2014).

[117] Takeuchi, I., Famodu, O. O., Read, J. C., Aronova, M. A., Chang, K.-S., Craciunescu, C., Lofland, S. E., Wuttig, M., Wellstood, F. C., Knauss, L. and Orozco, A. Identification of novel compositions of ferromagnetic shape-memory alloys using composition spreads. Nat. Mater. 2, 180-184 (2003).

[118] Es'kov, A. V., Karmanenko, S. F., Pakhomov, O. V. and Starkov, A. S. Simulation of a solid-state cooler with electrocaloric elements. Phys. Solid State+ 51, 1574-1577 (2009).

[119] Hwalek, J. and Carr, E. F. A Liquid Crystal "Heat Switch". Heat Transfer Eng. 8, 36-39 (1987).

[120] Epstein, R. I. and Malloy, K. J. Electrocaloric devices based on thin-film heat switches. J. Appl. Phys. 106, 064509 (2009).

[121] Chang, C. W., Okawa, D., Majumdar, A. and Zettl, A. Solid-State Thermal Rectifier. Science 314, 1121-1124 (2006).

[122] Kobayashi, W., Teraoka, Y. and Terasaki, I. An oxide thermal rectifier. Appl. Phys. Lett. 95, 171905 (2009).

[123] Castán, T., Planes, A. and Saxena, A. Thermodynamics of ferrotoroidic materials: Toroidocaloric effect. Phys. Rev. B 85, 144429 (2012). 
[124] Lu, S. G., Fang, Z., Furman, E., Wang, Y., Zhang, Q. M., Mudryk, Y., Gschneidner Jr., K. A., Pecharsky, V. K. and Nan, C. W. Thermally mediated multiferroic composites for the magnetoelectric materials. Appl. Phys. Lett. 96, 102902 (2010).

[125] Ohno, H., Chiba, D., Matsukura, F., Omiya, T., Abe, E., Dietl, T., Ohno, Y., Ohtani, K. Electric-Field control of ferromagnetism. Nature 408, 944-946 (2000).

[126] Wada, H. and Tanabe, Y. Giant magnetocaloric effect of $\mathrm{MnAs}_{1-x} \mathrm{Sb}_{x}$. Appl. Phys. Lett. 79, 3302-3304 (2001).

[127] Tegus, O. Brück, E., Buschow, K. H. J. and de Boer, F. R. Transition-metal-based magnetic refrigerants for room-temperature applications. Nature 415, 150-152 (2002).

[128] Trung, N. T., Zhang, L., Caron, L., Buschow, K. H. J. and Brück, E. Giant magnetocaloric effects by tailoring the phase transitions. Appl. Phys. Lett. 96, 172504 (2010).

[129] Hu, F.-X., Shen, B.-G., Sun, J.-R. and Wu, G.-H. Large magnetic entropy change in a Heusler alloy $\mathrm{Ni}_{52.6} \mathrm{Mn}_{23.1} \mathrm{Ga}_{24.3}$ single crystal. Phys. Rev. B 64, 132412 (2001).

[130] Pasquale, M., Sasso, C. P., Lewis, L. H., Giudici, L., Lograsso, T. and Schlagel, D. Magnetostructural transition and magnetocaloric effect in $\mathrm{Ni}_{55} \mathrm{Mn}_{20} \mathrm{Ga}_{25}$ single crystals. Phys. Rev. B 72, 094435 (2005).

[131] Krenke, T., Duman, E., Acet, M., Wassermann, E. F., Moya, X., Mañosa, Ll. and Planes, A. Inverse magnetocaloric effect in ferromagnetic Ni-Mn-Sn alloys. Nat. Mater. 4, 450-454 (2005).

[132] Khan, M., Ali, N. and Stadler, S. Inverse magnetocaloric effect in ferromagnetic $\mathrm{Ni}_{50} \mathrm{Mn}_{37+x} \mathrm{Sb}_{13-x}$ Heusler alloys. J. Appl. Phys. 101, 053919 (2007).

[133] Aksoy, S., Krenke, T., Acet, M., Wassermann, E. F., Moya, X., Mañosa, Ll. and Planes, A. Tailoring magnetic and magnetocaloric properties of martensitic transitions in ferromagnetic Heusler alloys. Appl. Phys. Lett. 91, 241916 (2007).

[134] Sandeman, K. G., Daou, R., Özcan, S., Durrell, J. H., Mathur, N. D. and Fray, D. J. Negative magnetocaloric effect from highly sensitive metamagnetism in CoMnSi $_{1-x} \mathrm{Ge}_{x}$. Phys. Rev. B 74, 224436 (2006).

[135] Shebanovs, L., Borman, K., Lawless, W. N. and Kalvane, A. Electrocaloric Effect in Some Perovskite Ferroelectric Ceramics and Multilayer Capacitors.

Ferroelectrics 273, 137-142 (2002). 
[136] Hagberg, J., Uusimäki, A. and Jantunen, H. Electrocaloric characteristics in reactive sintered $0.87 \mathrm{~Pb}\left(\mathrm{Mg}_{1 / 3} \mathrm{Nb}_{2 / 3}\right) \mathrm{O}_{3}-0.13 \mathrm{PbTiO}_{3}$. Appl. Phys. Lett. 92, 132909 (2008).

[137] Sebald, G., Seveyrat, L., Guyomar, D., Lebrun, L., Guiffard, B. and Pruvost, S. Electrocaloric and pyroelectric properties of $0.75 \mathrm{~Pb}\left(\mathrm{Mg}_{1 / 3} \mathrm{Nb}_{2 / 3}\right) \mathrm{O}_{3}-0.25 \mathrm{PbTiO}_{3}$ single crystals. J. Appl. Phys. 100, 124112 (2006).

[138] Olsen, R. B., Butler, W. F., Payne, D. A., Tuttle, B. A. and Held, P. C. Observation of a Polarocaloric (Electrocaloric) Effect of $2{ }^{\circ} \mathrm{C}$ in Lead Zirconate Modified with $\mathrm{Sn}^{4+}$ and $\mathrm{Ti}^{4+}$. Phys. Rev. Lett. 45, 1436-1438 (1980).

[139] Peng, B., Fan, H. and Zhang, Q. A Giant Electrocaloric Effect in Nanoscale Antiferroelectric and Ferroelectric Phases Coexisting in a Relaxor $\mathrm{Pb}_{0.8} \mathrm{Ba}_{0.2} \mathrm{ZrO}_{3}$ Thin Film at Room Temperature, Adv. Funct. Mater. 23, 2987-2992 (2013).

[140] Chen, H., Ren, T.-L., Wu, X.-M., Yang, Y. and Liu, L.-T. Giant electrocaloric effect in lead-free thin film of strontium bismuth tantalite. Appl. Phys. Lett. 94, 182902 (2009).

[141] Mischenko, A. S., Zhang, Q., Whatmore, R. W., Scott, J. F. and Mathur, N. D. Giant electrocaloric effect in the thin film relaxor ferroelectric $0.9 \mathrm{PbMg}_{1 / 3} \mathrm{Nb}_{2 / 3} \mathrm{O}_{3}-$ $0.1 \mathrm{PbTiO}_{3}$ near room temperature. Appl. Phys. Lett. 89, 242912 (2006).

[142] Correia, T. M., Young, J. S., Whatmore, R. W., Scott, J. F., Mathur, N. D. and Zhang, Q. Investigation of the electrocaloric effect in a $\mathrm{PbMg}_{1 / 3} \mathrm{Nb}_{2 / 3} \mathrm{O}_{3}-\mathrm{PbTiO}_{3}$ relaxor thin film. Appl. Phys. Lett. 95, 182904 (2009).

[143] Saranya, D., Chaudhuri, A. R., Parui, J. and Krupanidhi, S. B. Electrocaloric effect of PMN-PT thin films near morphotropic phase boundary. Bull. Mater. Sci. 32, 259-262 (2009).

[144] Liu, P. F., Wang, J. L., Meng, X. J., Yang, J., Dkhil, B. and Chu, J. H. Huge electrocaloric effect in Langmuir-Blodgett ferroelectric polymer thin films. New J. Phys. 12, 023035 (2010).

[145] Li, X., Qian, X.-S., Gu, H., Chen, X., Lu, S. G., Lin, M., Bateman, F. and Zhang, Q. M. Giant electrocaloric effect in ferroelectric poly(vinylidenefluoridetrifluoroethylene) copolymers near a first-order ferroelectric transition. Appl. Phys. Lett. 101, 132903 (2012).

[146] Nikitin, S. A., Skokov, K. P., Koshkid'ko, Y. S., Pastushenkov, Y. G. and Ivanova, T. I. Giant Rotating Magnetocaloric Effect in the Region of Spin-Reorientation Transition in the $\mathrm{NdCo}_{5}$ Single Crystal. Phys. Rev. Lett. 105, 137205 (2010). 
[147] Caron, L., Ou, Z. Q., Nguyen, T. T., Cam Thanh, D. T., Tegus, O. and Brück, E. On the determination of the magnetic entropy change in materials with first-order transitions. J. Magn. Magn. Mater. 321, 3559 (2009).

[148] Crossley, S., PhD thesis, University of Cambridge (2013). Available at www.repository.cam.ac.uk/handle/1810/245063.

[149] Moore, J. D., Skokov, K. P., Liu, J. and Gutfleisch, O. Procedure for numerical integration of the magnetocaloric effect. J. Appl. Phys. 112, 063920 (2012).

[150] Bai, Y., Ding, K. Zheng, G.-P., Shi, S.-Q. and Qiao, L. Entropy-change measurement of electrocaloric effect of $\mathrm{BaTiO}_{3}$ single crystal. Phys. Stat. Sol. A 209, 941-944 (2012). 


\section{Box 1: Glossary of terms and symbols}

Caloric materials show reversible thermal changes, known as caloric effects, due to changes in applied driving field. Caloric materials and caloric effects are named according to the nature of the applied driving field, or according to the sign of the caloric effect, as described below.

Magnetocaloric materials show reversible thermal changes in response to changes of applied magnetic field $\Delta \mathbf{H}^{\dagger}$

Electrocaloric materials show reversible thermal changes in response to changes of applied electric field $\Delta \mathbf{E}$.

Mechanocaloric materials show reversible thermal changes in response to changes of applied stress field $\Delta \sigma$.

Elastocaloric materials show mechanocaloric effects in response to changes of uniaxial stress $\Delta \sigma_{\mathrm{u}}$. Textbooks use 'piezocaloric' for 'elastocaloric'.

Barocaloric materials show mechanocaloric effects in response to changes of isotropic stress, i.e. changes in hydrostatic pressure $\Delta p$. 
Conventional caloric materials* show $\Delta T>0, \Delta S<0$ and $Q<0$ when the magnitude of the driving field is increased. They arise at transitions between a high-temperature state whose zero-field order parameter is small or zero, and a low-temperature state whose zero-field order parameter is large.

Inverse caloric materials* show $\Delta T<0, \Delta S>0$ and $Q>0$ when the magnitude of the driving field is increased. They arise at transitions between a low-temperature state whose zero-field order parameter is small or zero, and a high-temperature state whose zero-field order parameter is large.

Multicaloric materials can support more than one type of caloric effect.

Hitherto unobserved multicaloric effects would arise if more than one type of caloric effect were driven simultaneously or sequentially in a single sample.

${ }^{\dagger} \mathrm{MC}$ effects are normally driven by changes in field magnitude, but rotating fields can drive MC effects via magnetostructural spin-reorientation transitions ${ }^{146}$.

*For elastocaloric effects, we suggest employing these two definitions for compressive stress, and inverting the six inequalities for tensile stress.

Relaxor ferroelectrics appear to possess broad ferroelectric phase transitions when electrically interrogated on practical timescales, but in reality they are dipolar glasses 
with no spontaneous ferroelectric phase transitions due to chemical disorder. 


\section{Box 2: Indirect and quasi-direct methods}

Values of isothermal $\Delta S$ may be obtained via the indirect and quasi-direct methods described below. It is common to normalise by mass, and where necessary assume constant density given that sample volumes typically change by less than $\sim 1 \%$ when driving caloric transitions.

\section{Indirect methods}

Values of $\Delta S$ are obtained via the thermodynamic analysis of experimental data that records the influence of temperature and field on the magnitude of the local order parameter (magnetization $M$, polarization $P$, strain $\varepsilon$, or volume $V$ ). Ideally, the order parameter should be obtained in thermodynamic equilibrium as a single-valued function of temperature and field. A single-valued function of temperature may be achieved near second-order phase transitions, whereas near first-order phase transitions it is acceptable to use non-equilibrium data collected directly after thermal excursions away from the hysteretic regime. However, these excursions are only essential for strongly hysteretic transitions ${ }^{49,147}$. A single-valued function of field precludes any hysteresis associated with ferroic domains or field-driven transitions ${ }^{148}$, but limited hysteresis may be tolerated in practice.

Values of isothermal $Q$ are obtained from $Q=T \Delta S$.

There are two types of indirect method, described below. 
Maxwell method. Values of $\Delta S$ are obtained by integrating one side of the relevant Maxwell relation [e.g. $\mu_{0}(\partial M / \partial T)_{H}=(\partial S / \partial H)_{T}$ ] as shown below, where 'i' and 'f' denote initial and final values, and where the prime indicates the dummy variable of integration. The order parameter is typically measured as a function of field at different temperatures. For second-order transitions, this may be achieved in a single temperature sweep. For strongly hysteretic first-order transitions, multiple temperature sweeps are required $^{147}$, and therefore one may equally measure the order parameter as a function of temperature at different fields.

\begin{tabular}{|c|l|}
\hline Magnetocaloric & $\Delta S\left[\mathrm{~J} \mathrm{~K}^{-1} \mathrm{~m}^{-3}\right]=\mu_{0} \int_{H_{\mathrm{i}}}^{H_{\mathrm{f}}}(\partial M / \partial T)_{H^{\prime}} \mathrm{d} H^{\prime}$ \\
\hline Electrocaloric & $\Delta S\left[\mathrm{~J} \mathrm{~K}^{-1} \mathrm{~m}^{-3}\right]=\int_{E_{\mathrm{i}}}^{E_{\mathrm{f}}}(\partial P / \partial T)_{E^{\prime}} \mathrm{d} E^{\prime}$ \\
\hline Elastocaloric & $\Delta S\left[\mathrm{~J} \mathrm{~K}^{-1} \mathrm{~m}^{-3}\right]=\int_{\sigma_{\mathrm{u}}^{\mathrm{f}}}^{\sigma_{\mathrm{u}}^{\mathrm{f}}}(\partial \varepsilon / \partial T)_{\sigma_{\mathrm{u}^{\prime}}} \mathrm{d} \sigma_{\mathrm{u}^{\prime}}$ \\
\hline Barocaloric & $\Delta S\left[\mathrm{~J} \mathrm{~K}^{-1}\right]=-\int_{p_{\mathrm{i}}}^{p_{\mathrm{f}}}(\partial V / \partial T)_{p^{\prime}} \mathrm{d} p^{\prime}$ \\
\hline
\end{tabular}

One may obtain accurate values of $\Delta T$ by measuring the field and temperature dependence of $c$, and inserting the resulting factor of $-T / c$ into the relevant integrand above, as shown ${ }^{149}$ for the MC materials $\mathrm{Gd}$ and $\mathrm{LaFe}_{11.6} \mathrm{Si}_{1.4}$. However, this strategy represents a quasi-direct method that obviates the need to measure the order parameter.

In practice, values of $\Delta T$ may be estimated using $\Delta T \simeq(T \Delta S) / c$ in the limit $\Delta T \ll T$, assuming a constant value of $T$, and assuming a constant value of specific heat capacity $c$ despite the transition. For second-order transitions, reasonable agreement between direct 
and indirect methods is possible ${ }^{2,52,149}$ as there may in practice be no sharp peak in $c(T)$ at zero field. For first-order transitions, reasonable agreement may inevitably be achieved using an effective value of $c$ that lies between the (possibly unresolved) peak and a value away from the transition ${ }^{49,133,136}$, but there is no systematic way of choosing this effective value. However, for both first and second-order transitions, values of $\Delta S$ may be accurately converted into values of $\Delta T$ by using $c(T)$ at zero field to identify adiabats in entropy-temperature space ${ }^{17,42,54}$, or more elegantly in field-temperature space ${ }^{148}$.

Clausius-Clapeyron method. This is only valid for first-order transitions, and fails to account for the caloric effects that arise in each of the interconvertible phases themselves. However, these background effects are normally much smaller than caloric effects at transitions of interest, and therefore this method is nominally equivalent to the Maxwell method. One typically measures the temperature dependence of the order parameter at fixed fields, in order to determine the field dependence of equilibrium transition temperature $T_{0}$. This field-driven shift in $T_{0}$ may be obtained from transition start or finish temperatures on cooling or warming, and it directly yields $\Delta T$ as a function of field in the transition regime. Values of $\Delta S$ for the fully driven transition alone are then obtained using the appropriate Clausius-Clapeyron equation below, with the change in order parameter across the transition indicated by the subscript " 0 ". By taking transition width into account, it is straightforward to establish the field dependence of $\Delta S$.

\begin{tabular}{|c|l|}
\hline Magnetocaloric & $\Delta S\left[\mathrm{~J} \mathrm{~K}^{-1} \mathrm{~m}^{-3}\right]=-\mu_{0} \Delta M_{0}\left(\mathrm{~d} T_{0} / \mathrm{d} H\right)^{-1}$ \\
\hline Electrocaloric & $\Delta S\left[\mathrm{~J} \mathrm{~K}^{-1} \mathrm{~m}^{-3}\right]=-\Delta P_{0}\left(\mathrm{~d} T_{0} / \mathrm{d} E\right)^{-1}$ \\
\hline Elastocaloric & $\Delta S\left[\mathrm{~J} \mathrm{~K}^{-1} \mathrm{~m}^{-3}\right]=-\Delta \varepsilon_{0}\left(\mathrm{~d} T_{0} / \mathrm{d} \sigma_{\mathrm{u}}\right)^{-1}$ \\
\hline Barocaloric & $\Delta S\left[\mathrm{~J} \mathrm{~K}^{-1}\right]=\Delta V_{0}\left(\mathrm{~d} T_{0} / \mathrm{d} p\right)^{-1}$ \\
\hline
\end{tabular}




\section{Quasi-direct methods}

Values of $\Delta S$ may be obtained via the heat-capacity ${ }^{17,54,150}$ and heat-flux ${ }^{20,31,32,44,49}$ methods described below, but the latter is normally only sufficiently sensitive for first-order transitions. The parameters $X_{\mathrm{i}}$ and $X_{\mathrm{f}}$ represent initial and final fields $(X=H$, $E, \sigma_{\mathrm{u}}$ or $p$ ), with $T_{1}$ freely chosen below the transition temperature for both conventional and inverse caloric effects.

Values of $Q$ may be obtained by removing the factor of $1 / T^{\prime}$ from the integrand, and should match $Q=T \Delta S$ for sharp (first-order) transitions.

Values of $\Delta T$ may be calculated by first removing the second term in the integrand to obtain the change in entropy $\Delta S\left(T, X_{\mathrm{f}}\right)$ on heating from $T_{1}$ to $T$, and then evaluating $\Delta S\left(T, X_{\mathrm{i}}\right)$ in a similar manner. This permits the isentropic temperature difference between the two functions thus obtained to be evaluated at the desired start or finish temperature.

Heat-capacity method. The temperature dependence of heat capacity $C$ is measured in $X_{\mathrm{i}}$ and $X_{\mathrm{f}}$ to yield:

$$
\Delta S\left(T, X_{\mathrm{f}}-X_{\mathrm{i}}\right)\left[\mathrm{J} \mathrm{K}^{-1}\right] \simeq \int_{T_{1}}^{T}\left[C\left(T^{\prime}, X_{\mathrm{f}}\right)-C\left(T^{\prime}, X_{\mathrm{i}}\right)\right] \frac{\mathrm{d} T^{\prime}}{T^{\prime}},
$$

with precise equivalence as $T_{1} \rightarrow 0$. 
Heat-flux method. The temperature dependence of heat flux $\mathrm{d} Q / \mathrm{d} T$ is measured in $X_{\mathrm{i}}$ and $X_{\mathrm{f}}$, and the above equation is employed with $C$ replaced by $\mathrm{d} Q / \mathrm{d} T$. 


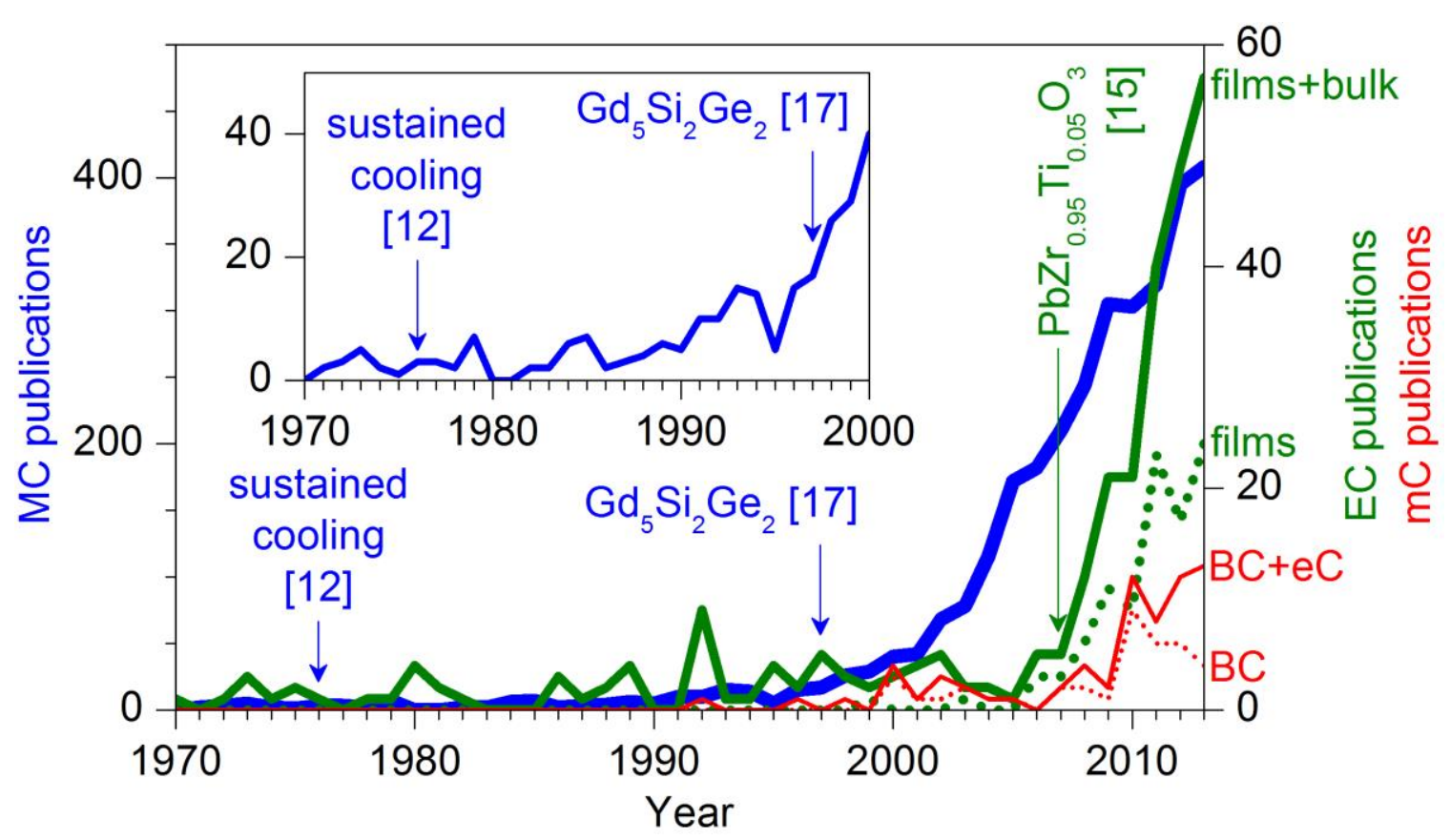

Figure 1. Caloric publications in recent decades. Magnetocaloric (MC) research activity was stimulated by the 1976 report $^{12}$ of sustained cooling near room temperature, and by the 1997 report ${ }^{17}$ of giant effects in $\mathrm{Gd}_{5} \mathrm{Si}_{2} \mathrm{Ge}_{2}$. Inset, detail of main figure showing increase of MC research prior to 1997 . Electrocaloric (EC) research activity on film and bulk samples was stimulated by the 2006 report ${ }^{15}$ of giant effects in films of $\mathrm{PbZr}_{0.95} \mathrm{Ti}_{0.05} \mathrm{O}_{3}$, and the subsequent 2008 report on polymer films ${ }^{16}$ (bulk and film are distinguished by growth methodology rather than thickness). Elastocaloric (eC) and barocaloric (BC) research are described collectively as mechanocaloric $(\mathrm{mC})$ research. The recent increase in $\mathrm{mC}$ research activity follows a period in which some years saw $\mathrm{BC}$ but no eC publications. All five plots are subject to errors associated with search terminology, and include cryogenic studies. 


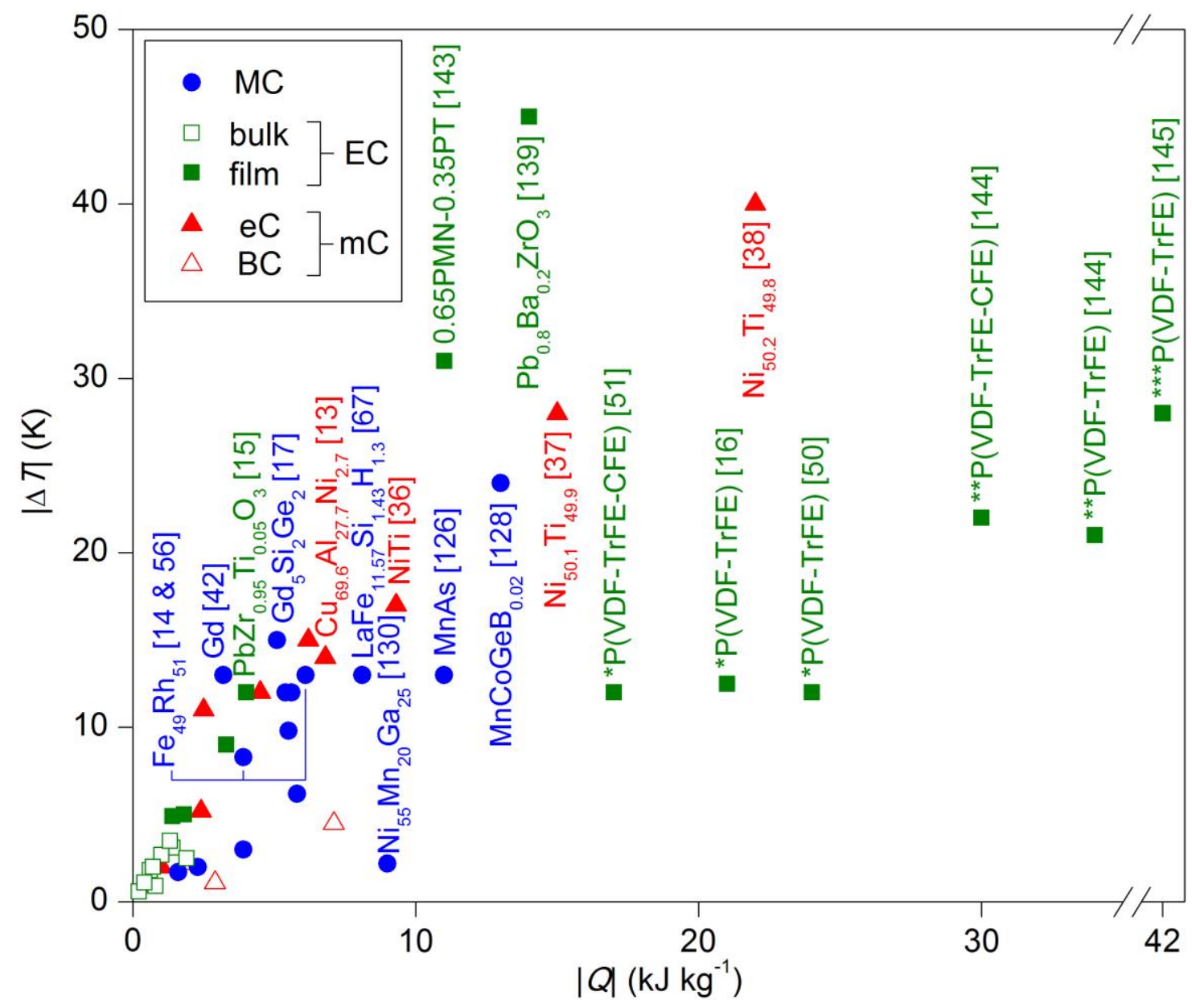

Figure 2. Selected caloric effects at phase transitions near and away from room temperature. For the caloric materials of Tables 1-3, adiabatic temperature change $|\Delta T|$ is plotted against isothermal heat $|Q|$, as both materials parameters are relevant for applications. The normalization of heat by mass strongly favours the low-density EC polymer films, which are roughly four times less dense than the EC ceramics. Abbreviated formulae are defined in Table 2 footnotes. Plots with molar and volume normalization appear in Supplementary Information. 


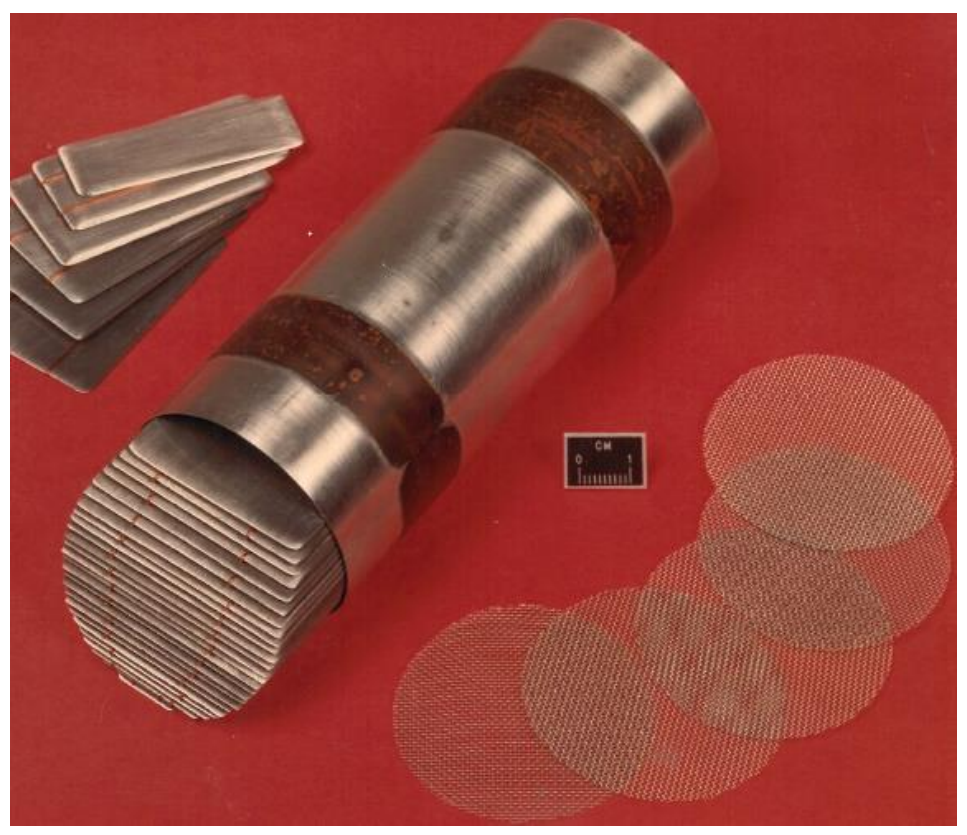

Figure 3. Selected components from the 1978 magnetocaloric refrigerator prototype with a record temperature span of $\boldsymbol{T}_{\mathbf{h}}-\boldsymbol{T}_{\mathbf{c}}=\mathbf{8 0} \mathbf{K}$. Brown improved ${ }^{105}$ upon his 1976 prototype $^{12}$, which spanned $T_{\mathrm{h}}-T_{\mathrm{c}}=47 \mathrm{~K}$, by enlarging it and reducing turbulence in the regenerator fluid. This reduction in turbulence was achieved by streamlining the ends of the Gd plates (shown in and out of canister housing), and by placing at each end of the canister a wire screen (examples are shown bottom right). Image and information courtesy of G. V. Brown. 


\section{Table 1. Selected magnetocaloric effects at phase transitions near and away from}

room temperature. Isothermal entropy change $|\Delta S|$, adiabatic temperature change $|\Delta T|$, and isothermal heat $|Q|$, at starting temperature $T$, due to changes of magnetic field $\mu_{0}|\Delta H|$. Bold entries denote data derived from direct measurements. Italicised entries denote data derived from quasi-direct measurements. Underlined entries denote data derived from indirect measurements. Bracketed entries denote data derived via $c \Delta T \simeq T \Delta S=Q$ using zero-field specific heat capacity $c$. For all entries, $Q=T \Delta S$. For independently measured isothermal processes, starting temperatures may differ slightly from the values shown. All starting fields were zero. Molar and volume normalizations of entropy change and heat are shown in Table S1 of Supplementary Information. 
Table 1

\begin{tabular}{|c|c|c|c|c|c|c|c|}
\hline & MC material & $\begin{array}{l}T \\
\mathrm{~K}\end{array}$ & $\begin{array}{c}|\Delta S| \\
\mathrm{J} \mathrm{K}^{-1} \mathrm{~kg}^{-1}\end{array}$ & $\begin{array}{c}|\Delta T| \\
\mathrm{K}\end{array}$ & $\begin{array}{c}|Q| \\
\mathrm{kJ} \mathrm{kg}^{-1}\end{array}$ & $\begin{array}{c}\mu_{0}|\Delta H| \\
\mathrm{T}\end{array}$ & Ref. \\
\hline \multirow{9}{*}{ 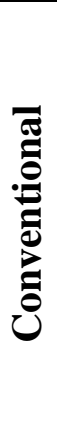 } & $\mathrm{Gd}_{5} \mathrm{Si}_{2} \mathrm{Ge}_{2}$ & 280 & $\underline{19}$ & 15 & $\underline{5.1}$ & 5 & 17 \\
\hline & $\mathrm{Gd}$ & 294 & $\underline{11}$ & 13 & $\underline{3.2}$ & 5 & 42 \\
\hline & MnAs & 317 & $\overline{34}$ & 13 & $\underline{11}$ & 5 & 126 \\
\hline & $\mathrm{MnFeP}_{0.45} \mathrm{As}_{0.55}$ & 308 & $\underline{18}$ & [9.8] & $\underline{5.5}$ & 5 & 127 \\
\hline & $\mathrm{Mn}_{1.24} \mathrm{Fe}_{0.71} \mathrm{P}_{0.46} \mathrm{Si}_{0.54}$ & 320 & $\underline{12}$ & 3.0 & $\underline{3.9}$ & 1 & 58 \\
\hline & $\mathrm{MnCoGeB}_{0.02}$ & 277 & $\underline{47}$ & [24] & $\underline{13}$ & 5 & 128 \\
\hline & $\mathrm{LaFe}_{11.57} \mathrm{Si}_{1.43} \mathrm{H}_{1.3}$ & 291 & $\underline{28}$ & 13 & $\underline{8.1}$ & 5 & 67 \\
\hline & $\mathrm{Ni}_{52.6} \mathrm{Mn}_{23.1} \mathrm{Ga}_{24.3}$ & 300 & $\underline{18}$ & [12] & $\underline{5.4}$ & 5 & 129 \\
\hline & $\mathrm{Ni}_{55} \mathrm{Mn}_{20} \mathrm{Ga}_{25}$ & 311 & $\underline{29}$ & 2.2 & $\underline{9.0}$ & 5 & 130 \\
\hline \multirow{7}{*}{ 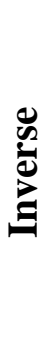 } & $\mathrm{Ni}_{50} \mathrm{Mn}_{37} \mathrm{Sn}_{13}$ & 299 & $\underline{18}$ & [12] & $\overline{5.4}$ & 5 & 131 \\
\hline & $\mathrm{Ni}_{50} \mathrm{Mn}_{38} \mathrm{Sb}_{12}$ & 297 & $\underline{19}$ & [12] & $\underline{5.6}$ & 5 & 132 \\
\hline & $\mathrm{Ni}_{50} \mathrm{Mn}_{34} \mathrm{In}_{14} \mathrm{Ga}_{2}$ & 260 & 9.0 & 2.0 & 2.3 & 5 & 133 \\
\hline & $\mathrm{Ni}_{45.2} \mathrm{Mn}_{36.7} \operatorname{In}_{13} \mathrm{Co}_{5.1}$ & 318 & $\underline{18}$ & 6.2 & $\underline{5.8}$ & 2 & 93 \\
\hline & CoMnSi & 250 & $\underline{6.5}$ & 1.7 & $\underline{1.6}$ & 5 & 134 \\
\hline & $\dagger \mathrm{Fe}_{49} \mathrm{Rh}_{51}$ & 308 & [20] & 13 & {$[\overline{6.1}]$} & 2 & 14 \\
\hline & $\dagger \dagger \mathrm{Fe}_{49} \mathrm{Rh}_{51}$ & 308 & 13 & 8.3 & 3.9 & 2.5 & 56 \\
\hline
\end{tabular}

†annealed in vacuum at $1300 \mathrm{~K}$ for $72 \mathrm{~h}$, then quenched to $278 \mathrm{~K}$ ††annealed in vacuum at $1273 \mathrm{~K}$ for $10 \mathrm{~h}$, then quenched to $273 \mathrm{~K}$ 
Table 2. Selected electrocaloric effects at phase transitions near and away from room temperature. Isothermal entropy change $|\Delta S|$, adiabatic temperature change $|\Delta T|$, and isothermal heat $|Q|$, at starting temperature $T$, due to changes of electric field $|\Delta E|$. Bold entries denote data derived from direct measurements. Italicised entries denote data derived from quasi-direct measurements. Underlined entries denote data derived from indirect measurements. Bracketed entries denote data derived via $c \Delta T \simeq T \Delta S=Q$ using zero-field specific heat capacity $c$. For all entries, $Q=T \Delta S$. For independently measured isothermal processes, starting temperatures may differ slightly from the values shown. All starting fields were zero, except for $\mathrm{PbZr}_{0.95} \mathrm{Ti}_{0.05} \mathrm{O}_{3}$ where $E_{\mathrm{i}}=296 \mathrm{kV} \mathrm{cm}$. Relaxors are denoted (r). Molar and volume normalizations of entropy change and heat are shown in Table S2 of Supplementary Information. 
Table 2

\begin{tabular}{|c|c|c|c|c|c|c|c|}
\hline & EC material & $\begin{array}{l}T \\
\mathrm{~K}\end{array}$ & $\begin{array}{c}|\Delta S| \\
\mathrm{J} \mathrm{K}^{-1} \mathrm{~kg}^{-1}\end{array}$ & $\begin{array}{c}|\Delta T| \\
\mathrm{K}\end{array}$ & $\begin{array}{c}|Q| \\
\mathrm{kJ} \mathrm{kg}^{-1}\end{array}$ & $\begin{array}{c}|\Delta E| \\
\mathrm{kV} \mathrm{cm}\end{array}$ & Ref. \\
\hline \multirow{11}{*}{ 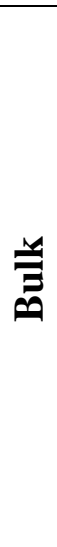 } & $\mathrm{KH}_{2} \mathrm{PO}_{4}$ & 125 & $\underline{1.0}$ & {$[1.0]$} & $\underline{0.4}$ & 10 & 71 \\
\hline & $\mathrm{PbZr}_{0.455} \mathrm{Sn}_{0.455} \mathrm{Ti}_{0.09} \mathrm{O}_{3}$ & 317 & [1.8] & 1.6 & {$[0.6]$} & 30 & 46 \\
\hline & $\mathrm{PbSc}_{0.5} \mathrm{Ta}_{0.5} \mathrm{O}_{3}$ & 295 & {$[2.1]$} & 1.8 & {$[0.6]$} & 25 & 135 \\
\hline & $\mathrm{BaTiO}_{3}$ & 397 & 2.1 & [0.9] & 0.8 & 4 & 49 \\
\hline & (r) $\mathrm{Ba}_{0.65} \mathrm{Sr}_{0.35} \mathrm{Ti}_{0.997} \mathrm{Mn}_{0.003} \mathrm{O}_{3}$ & 293 & 4.8 & [3.1] & 1.4 & 130 & 79 \\
\hline & (r) $0.87 \mathrm{PMN}-0.13 \mathrm{PT}$ & 343 & {$[\overline{0.6}]$} & 0.6 & {$[\overline{0.2}]$} & 24 & 136 \\
\hline & (r) $0.75 \mathrm{PMN}-0.25 \mathrm{PT}$ & 383 & 1.0 & {$[1.1]$} & 0.4 & 25 & 137 \\
\hline & (r) $† 0.70 \mathrm{PMN}-0.30 \mathrm{PT}$ & 429 & [2.3] & 2.7 & {$[1.0]$} & 90 & 82 \\
\hline & $(\mathrm{r}) \dagger \dagger 0.90 \mathrm{PMN}-0.10 \mathrm{PT}$ & 400 & [3.2] & 3.5 & [1.3] & 160 & $t$ \\
\hline & $* \mathrm{PNZS}$ & 434 & [4.3] & 2.5 & [1.9] & 30 & 47 \\
\hline & $* *$ PNZS & 423 & {$[1.7]$} & 2.0 & {$[0.7]$} & 20 & 138 \\
\hline \multirow{13}{*}{ 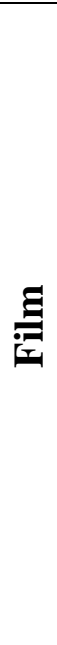 } & $\mathrm{PbZr}_{0.95} \mathrm{Ti}_{0.05} \mathrm{O}_{3}$ & 499 & 8.0 & [12] & $\underline{4.0}$ & 480 & 15 \\
\hline & (r) $\mathrm{Pb}_{0.8} \mathrm{Ba}_{0.2} \mathrm{ZrO}_{3}$ & 290 & $\underline{47}$ & [45] & $\underline{14}$ & 598 & 139 \\
\hline & (r) $\mathrm{SrBi}_{2} \mathrm{Ta}_{2} \mathrm{O}_{9}$ & 565 & $\overline{2.4}$ & [4.9] & $\overline{1.4}$ & 600 & 140 \\
\hline & (r) $0.90 \mathrm{PMN}-0.10 \mathrm{PT}$ & 348 & $\overline{5.3}$ & {$[5.0]$} & $\overline{1.8}$ & 895 & 141 \\
\hline & (r) $0.93 \mathrm{PMN}-0.07 \mathrm{PT}$ & 298 & $\underline{11}$ & [9.0] & $\overline{3.3}$ & 723 & 142 \\
\hline & (r) $0.65 \mathrm{PMN}-0.35 \mathrm{PT}$ & 413 & $\overline{28}$ & [31] & $\overline{11}$ & 747 & 143 \\
\hline & $* \mathrm{P}(\mathrm{VDF}-\mathrm{TrFE})$ & 353 & $\underline{60}$ & [12.5] & $\underline{21}$ & 2090 & 16 \\
\hline & $* \mathrm{P}(\mathrm{VDF}-\mathrm{TrFE})$ & 340 & {$[\overline{70}]$} & 12 & {$[\overline{24}]$} & 1200 & 50 \\
\hline & $* * \mathrm{P}(\mathrm{VDF}-\mathrm{TrFE})$ & 390 & [87] & $\underline{21}$ & [34] & 3000 & 144 \\
\hline & $* * * \mathrm{P}(\mathrm{VDF}-\mathrm{TrFE})$ & 323 & 130 & {$[\overline{28}]$} & 42 & 1800 & 145 \\
\hline & (r) *P(VDF-TrFE-CFE) & 328 & $\underline{64}$ & [12.5] & $\underline{21}$ & 3070 & 16 \\
\hline & (r) *P(VDF-TrFE-CFE) & 318 & {$[\overline{55}]$} & 12 & {$[\overline{17}]$} & 1700 & 51 \\
\hline & $(\mathrm{r}) * * \mathrm{P}(\mathrm{VDF}-\mathrm{TrFE}-\mathrm{CFE})$ & 350 & $\underline{85}$ & {$[22]$} & $\underline{30}$ & 3500 & 144 \\
\hline
\end{tabular}

$\mathrm{PMN}=\mathrm{PbMg}_{1 / 3} \mathrm{Nb}_{2 / 3} \mathrm{O}_{3}, \mathrm{PT}=\mathrm{PbTiO}_{3}$

$*$ PNZS $=\mathrm{Pb}_{0.99} \mathrm{Nb}_{0.02}\left(\mathrm{Zr}_{0.75} \mathrm{Sn}_{0.20} \mathrm{Ti}_{0.05}\right)_{0.98} \mathrm{O}_{3}$

$* * \mathrm{PNZS}=\mathrm{Pb}_{0.99} \mathrm{Nb}_{0.02}\left[\left(\mathrm{Zr}_{0.73} \mathrm{Sn}_{0.27}\right)_{0.93} \mathrm{Ti}_{0.07}\right]_{0.98} \mathrm{O}_{3}$

$* \mathrm{P}(\mathrm{VDF}-\mathrm{TrFE})=$ poly $($ vinylidene fluoride-trifluoroethylene) $55 / 45 \mathrm{~mol} \%$

$* * \mathrm{P}(\mathrm{VDF}-\mathrm{TrFE})=$ poly $($ vinylidene fluoride-trifluoroethylene $) 70 / 30 \mathrm{~mol} \%$

$* * * \mathrm{P}(\mathrm{VDF}-\mathrm{TrFE})=$ poly $($ vinylidene fluoride-trifluoroethylene $) 65 / 35 \mathrm{~mol} \%$

$* \mathrm{P}(\mathrm{VDF}-\mathrm{TrFE}-\mathrm{CFE})=$ poly $($ vinylidene fluoride-trifluoroethylenechlorofluoroethylene $)$ 59.2/33.6/7.2 mol \%

$* * \mathrm{P}(\mathrm{VDF}-\mathrm{TrFE}-\mathrm{CFE})=$ poly $($ vinylidene fluoride-trifluoroethylenechlorofluoroethylene $)$ 56.2/36.3/7.6 mol\% $\dagger$ platelets of thickness 60-100 $\mu \mathrm{m}$

$\dagger \dagger$ thinned to $80 \mu \mathrm{m}$

\#. Uršič, B. Rožičč, Z. Kutnjak, J. Holc, M. Kosec, private communication 
Table 3. Selected mechanocaloric effects at phase transitions near and away from room temperature. Isothermal entropy change $|\Delta S|$, adiabatic temperature change $|\Delta T|$, and isothermal heat $|Q|$, at starting temperature $T$, due to changes of stress field $|\Delta \sigma|$. Bold entries denote data derived from direct measurements. Italicised entries denote data derived from quasi-direct measurements. Underlined entries denote data derived from indirect measurements. Bracketed entries denote data derived via $c \Delta T \simeq T \Delta S=Q$ using zero-field specific heat capacity $c$. For all entries, $Q=T \Delta S$. For independently measured isothermal processes, starting temperatures may differ slightly from the values shown. All starting fields were zero. Molar and volume normalizations of entropy change and heat are shown in Table S3 of Supplementary Information. 
Table 3

\begin{tabular}{|c|c|c|c|c|c|c|c|}
\hline & mC material & $\begin{array}{l}T \\
\mathrm{~K}\end{array}$ & $\begin{array}{c}|\Delta S| \\
\mathrm{J} \mathrm{K}^{-1} \mathrm{~kg}^{-1}\end{array}$ & $\begin{array}{c}|\Delta T| \\
\mathrm{K}\end{array}$ & $\begin{array}{c}|Q| \\
\mathrm{kJ} \mathrm{kg}^{-1}\end{array}$ & $\begin{array}{l}|\Delta \sigma| \\
\mathrm{GPa}\end{array}$ & Ref. \\
\hline \multirow{9}{*}{ త్ర } & $\mathrm{Cu}_{69.6} \mathrm{Al}_{27.7} \mathrm{Ni}_{2.7}$ & 308 & 22 & 14 & $\underline{6.8}$ & 0.15 & 13 \\
\hline & $\mathrm{Cu}_{68.1} \mathrm{Zn}_{15.8} \mathrm{Al}_{16.1}$ & 300 & $\underline{21}$ & [15] & $\overline{6.2}$ & 0.13 & 19 \\
\hline & $\mathrm{Cu}_{64.6} \mathrm{Zn}_{33.7} \mathrm{Sn}_{1.7}$ & 296 & $\underline{15}$ & 12 & $\underline{4.5}$ & 0.20 & 35 \\
\hline & NiTi & 295 & {$[\overline{32}]$} & 17 & {$[\overline{9.3}]$} & 0.65 & 36 \\
\hline & $\mathrm{Ni}_{50.1} \mathrm{Ti}_{49.9}$ & 343 & [45] & 28 & {$[15]$} & 0.90 & 37 \\
\hline & $\mathrm{Ni}_{50.2} \mathrm{Ti}_{49.8}$ & 296 & [74] & 40 & [22] & 0.80 & 38 \\
\hline & $\mathrm{Ni}_{50.7} \mathrm{Ti}_{49.3}$ & 295 & [8.5] & 11 & {$[2.5]$} & 0.03 & 110 \\
\hline & $\mathrm{Fe}_{68.8} \mathrm{Pd}_{31.2}$ & 240 & 4.2 & 2.0 & $\underline{1.0}$ & 0.10 & 86 \\
\hline & $\mathrm{Fe}_{49} \mathrm{Rh}_{51}$ & 311 & {$[\overline{7.8}]$} & 5.2 & {$[\overline{2.4}]$} & 0.53 & 56,57 \\
\hline \multirow{3}{*}{ U } & $\mathrm{Ni}_{49.26} \mathrm{Mn}_{36.08} \mathrm{In}_{14.66}$ & 293 & 24 & [4.5] & 7.1 & 0.26 & 20 \\
\hline & $\mathrm{Gd}_{5} \mathrm{Si}_{2} \mathrm{Ge}_{2}$ & 270 & 11 & 1.1 & 2.9 & 0.20 & 31 \\
\hline & $\mathrm{LaFe}_{11.33} \mathrm{Co}_{0.47} \mathrm{Si}_{1.2}$ & 237 & 8.7 & 2.2 & 2.0 & 0.20 & 32 \\
\hline
\end{tabular}




\begin{tabular}{|c|c|c|}
\hline Parameter & State variable? & Direct measurements? \\
\hline$\Delta T$ & $\checkmark$ & $\checkmark$ \\
\hline$\Delta S$ & $\checkmark$ & $\mathbf{x}$ \\
\hline$Q$ & $\mathbf{x}$ & $\checkmark$ \\
\hline
\end{tabular}

Table 4. State variables and direct measurements. Heat $Q$ is not a state variable and should therefore be written without $\Delta$. Entropy change $\Delta S$ cannot be measured directly. Changes $\Delta T$ in the state variable temperature can be measured directly. 


\title{
Supplementary Information
}

\section{Caloric materials near ferroic phase transitions}

\author{
X. Moya ${ }^{1,2}$, S. Kar-Narayan ${ }^{1}$ and N. D. Mathur ${ }^{1}$ \\ ${ }^{1}$ Department of Materials Science, University of Cambridge, 27 Charles Babbage Road, \\ Cambridge CB3 OFS, UK \\ ${ }^{2}$ Facultat de Física, Departament d'Estructura i Constituents de la Matèria, Universitat de \\ Barcelona, Martí i Franquès 1, E-08028 Barcelona, Catalonia, Spain
}

\section{Contents}

We reproduce Fig. 2 from the main paper as Fig. S1, and present two alternative versions:

- The Fig. S1 abscissa uses mass normalization.

- The Fig. S2 abscissa uses molar normalization.

- The Fig. S3 abscissa uses volume normalization.

The data used for Figs S1-S3 appear in Tables S1-S3, which are expanded with respect to Tables 1-3 in order to show all three normalizations.

Tables S4-S6 differ from Tables S1-S3 because performance is normalized by applied field. Normalization does not necessarily imply linearity.

All reference codes refer to the main paper. 


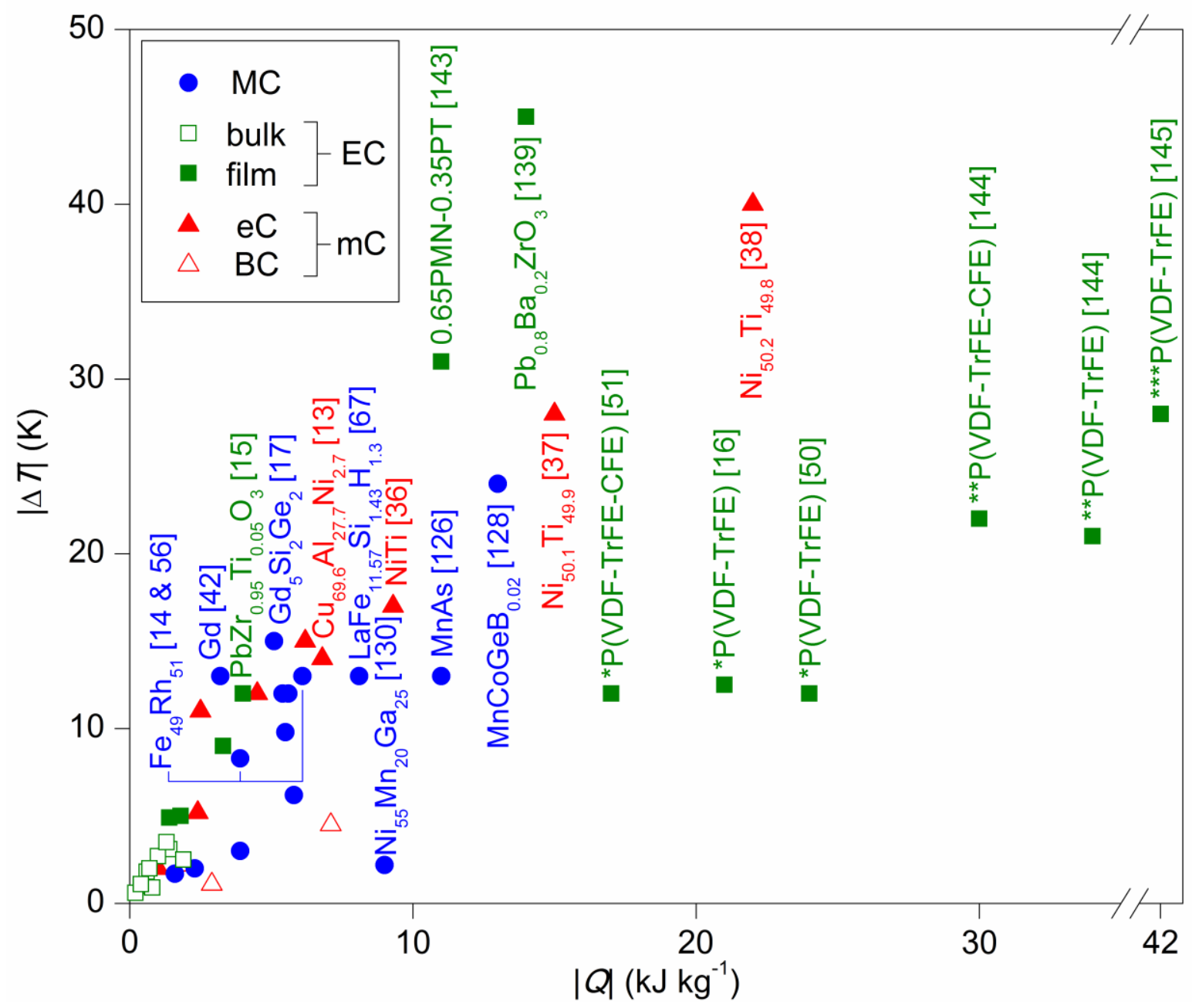

Figure S1. Mass normalized caloric effects at phase transitions near and away from room temperature. For the caloric materials of Tables S1-S3, adiabatic temperature change $|\Delta T|$ is plotted against isothermal heat $|Q|$, as both materials parameters are relevant for applications. The normalization of heat by mass strongly favours the lowdensity EC polymer films, which are roughly four times less dense than the EC ceramics. Abbreviated formulae for EC materials are defined in Table S2 footnotes. 


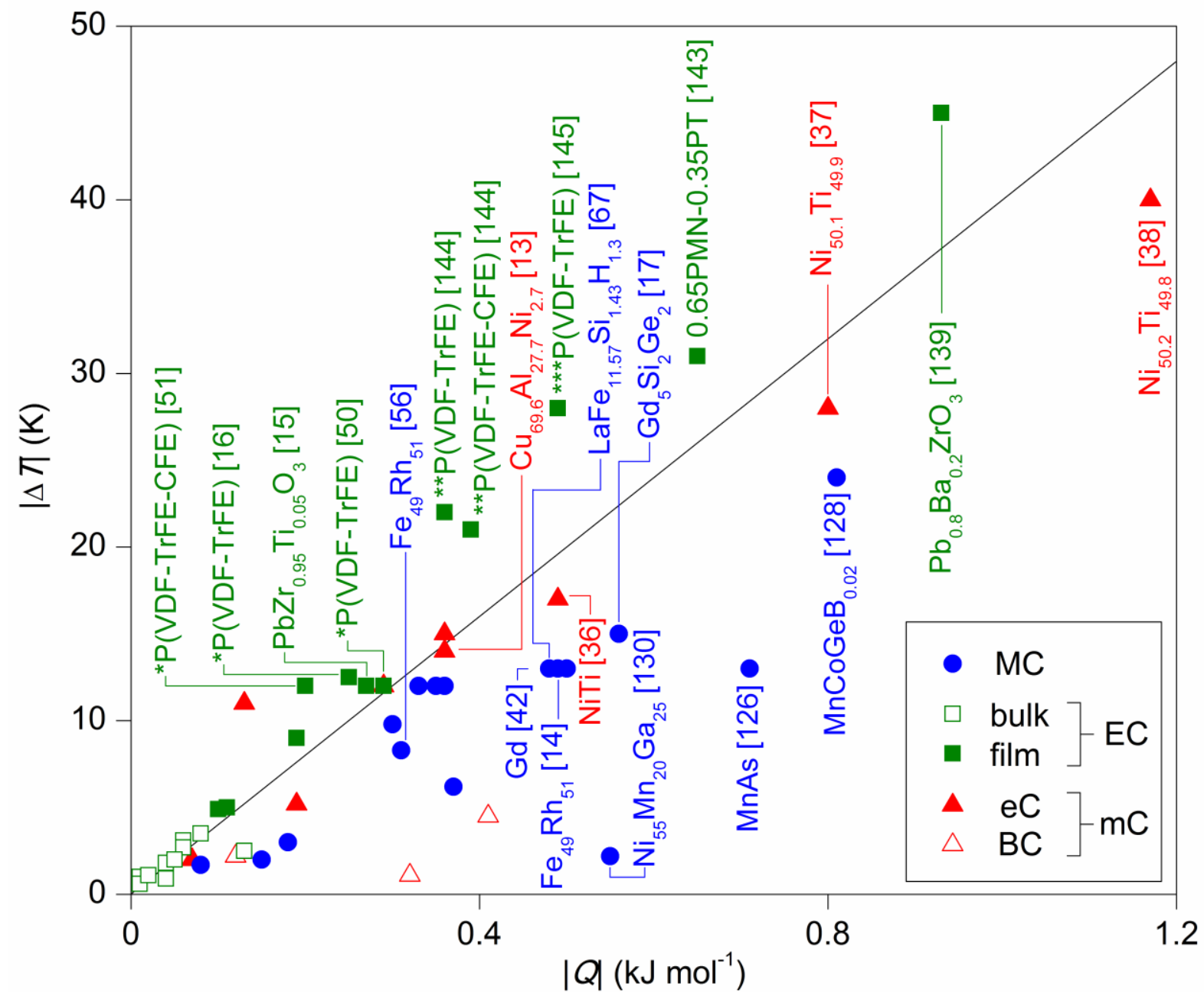

Figure S2. Molar normalized caloric effects at phase transitions near and away from room temperature. For the caloric materials of Tables S1-S3, adiabatic temperature change $|\Delta T|$ is plotted against isothermal heat $|Q|$ per mole of atoms. One mole of atoms was counted without consideration of species. Significant departures from $|\Delta T|=|Q| / 3 R$ (black line) may be due to identified/unidentified measurement errors $\left(R=8.3145 \mathrm{~J} \mathrm{~K}^{-1} \mathrm{~mol}^{-1}\right.$ is the universal gas constant). 


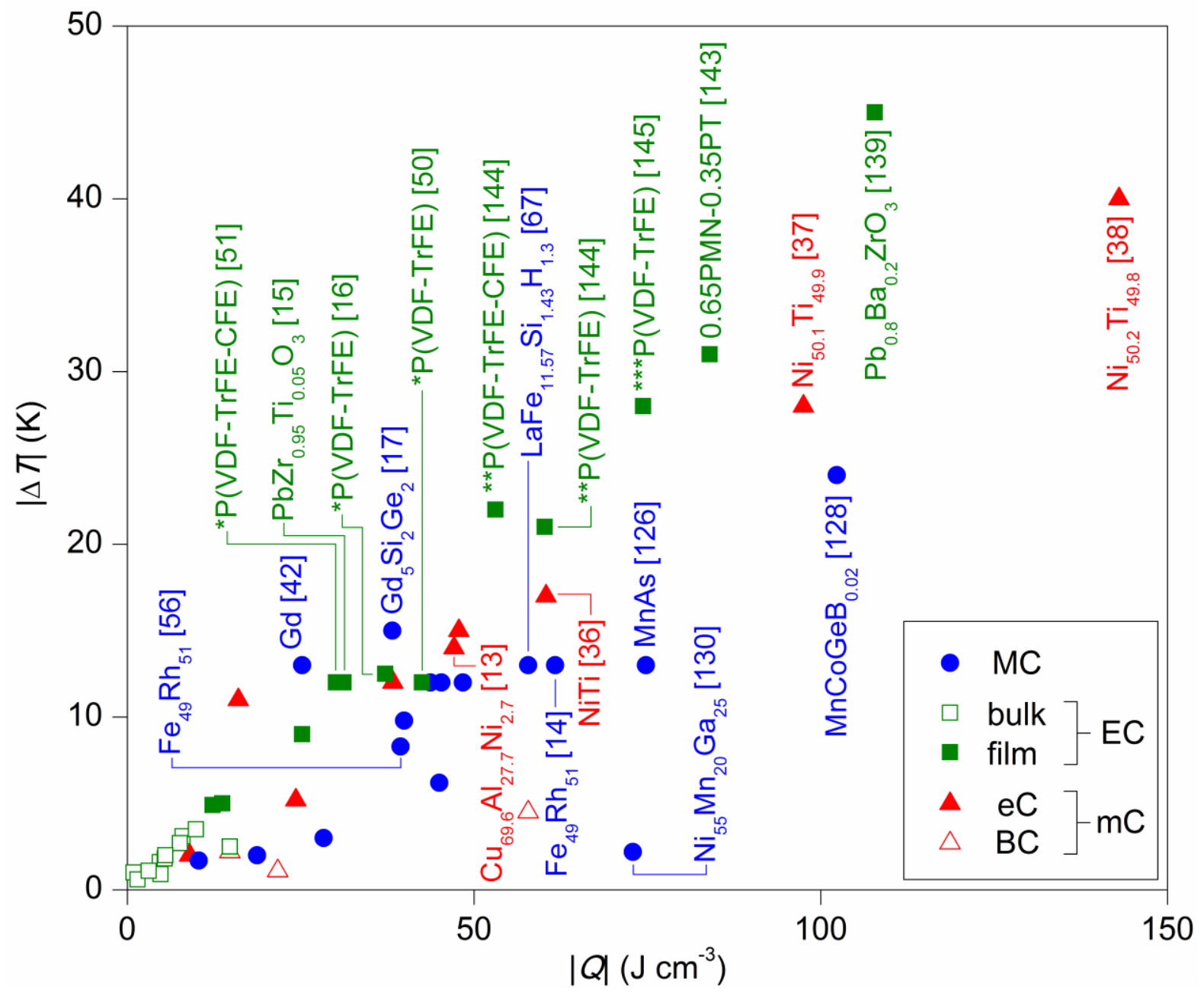

Figure S3. Volume normalized caloric effects at phase transitions near and away from room temperature. For the caloric materials of Tables S1-S3, adiabatic temperature change $|\Delta T|$ is plotted against isothermal heat $|Q|$ per unit volume. Data were calculated from mass-normalized values using values of density if available, or lattice parameters otherwise. 
Table S1. Mass, molar and volume normalized magnetocaloric effects at phase transitions near and away from room temperature. Isothermal entropy change adiabatic temperature change $|\Delta T|$, and isothermal heat $|Q|$, at starting temperature $T$, due to changes of magnetic field $\mu_{0}|\Delta H|$. For molar normalization, atoms were cou without consideration of species. Volume-normalized data were calculated from mass-normalized values using values of density if available, or lattice param otherwise. Bold entries denote data derived from direct measurements. Italicised entries denote data derived from quasidirect measurements. Underlined entries denote derived from indirect measurements. Bracketed entries denote data derived via $-c \Delta T \approx T \Delta S=Q$ using zero-field specific heat capacity $c$. For all entries, $Q=T \Delta S$. independently measured isothermal processes, starting temperatures may differ slightly from the values shown. All starting fields were zero.

\begin{tabular}{|c|c|c|c|c|c|c|c|c|c|c|c|}
\hline & MC material & $\begin{array}{l}T \\
\mathrm{~K}\end{array}$ & $\begin{array}{c}|\Delta S| \\
\mathrm{J} \mathrm{K}^{-1} \mathrm{~kg}^{-1}\end{array}$ & $\begin{array}{c}|\Delta S| \\
\mathrm{J} \mathrm{K}^{-1} \mathrm{~mol}^{-1}\end{array}$ & $\begin{array}{c}|\Delta S| \\
\mathrm{kJ} \mathrm{K}^{-1} \mathrm{~m}^{-3}\end{array}$ & $\begin{array}{c}|\Delta T| \\
\mathrm{K}\end{array}$ & $\begin{array}{c}|Q| \\
\mathrm{kJ} \mathrm{kg}^{-1}\end{array}$ & $\begin{array}{c}|Q| \\
\mathrm{kJ} \mathrm{mol}^{-1}\end{array}$ & $\begin{array}{c}|Q| \\
\mathrm{J} \mathrm{cm}^{-3}\end{array}$ & $\begin{array}{c}\mu_{0}|\Delta H| \\
\mathrm{T}\end{array}$ & Ref. \\
\hline \multirow{9}{*}{ 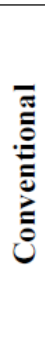 } & $\mathrm{Gd}$ & 294 & 11 & 1.73 & 86.6 & 13 & 3.2 & 0.50 & 25.2 & 5 & 42 \\
\hline & $\mathrm{Gd}_{5} \mathrm{Si}_{2} \mathrm{Ge}_{2}$ & 280 & $\underline{19}$ & $\underline{2.08}$ & $\overline{142}$ & 15 & $\overline{5.1}$ & $\overline{0.56}$ & $\overline{38.2}$ & 5 & 17 \\
\hline & MnAs & 317 & 34 & 2.21 & 231 & [13] & 11 & $\overline{0.71}$ & $\overline{74.8}$ & 5 & 126 \\
\hline & $\mathrm{MnFeP}_{0.45} \mathrm{As}_{0.55}$ & 308 & $\underline{18}$ & $\underline{0.99}$ & $\underline{131}$ & [9.8] & $\underline{5.5}$ & $\underline{0.30}$ & $\underline{39.9}$ & 5 & 127 \\
\hline & $\mathrm{Mn}_{1.24} \mathrm{Fe}_{0.71} \mathrm{P}_{0.46} \mathrm{Si}_{0.54}$ & 320 & $\underline{12}$ & $\underline{0.55}$ & $\underline{87.0}$ & 3.0 & 3.9 & $\underline{0.18}$ & $\underline{28.3}$ & 1 & 58 \\
\hline & $\mathrm{MnCoGeB}_{0.02}$ & 277 & $\underline{47}$ & $\underline{2.92}$ & $\underline{370}$ & [24] & $\underline{13}$ & $\underline{0.81}$ & $\underline{102}$ & 5 & 128 \\
\hline & $\mathrm{LaFe}_{11.57} \mathrm{Si}_{1.43} \mathrm{H}_{1.3}$ & 291 & $\underline{28}$ & $\underline{1.65}$ & 200 & 13 & 8.1 & $\underline{0.48}$ & 57.8 & 5 & 67 \\
\hline & $\mathrm{Ni}_{52.6} \mathrm{Mn}_{23.1} \mathrm{Ga}_{24.3}$ & 300 & $\underline{18}$ & $\underline{1.09}$ & $\underline{146}$ & [12] & 5.4 & $\underline{0.33}$ & 43.7 & 5 & 129 \\
\hline & $\mathrm{Ni}_{55} \mathrm{Mn}_{20} \mathrm{Ga}_{25}$ & 311 & $\underline{29}$ & 1.76 & $\underline{235}$ & 2.2 & $\overline{9.0}$ & 0.55 & $\overline{72.9}$ & 5 & 130 \\
\hline \multirow{7}{*}{ 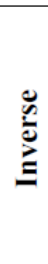 } & $\mathrm{Ni}_{50} \mathrm{Mn}_{37} \mathrm{Sn}_{13}$ & 299 & $\underline{18}$ & $\underline{1.17}$ & $\underline{161}$ & {$[12]$} & 5.4 & $\underline{0.35}$ & $\underline{48.4}$ & 5 & 131 \\
\hline & $\mathrm{Ni}_{50} \mathrm{Mn}_{38} \mathrm{Sb}_{12}$ & 297 & $\underline{19}$ & $\underline{1.23}$ & $\overline{154}$ & [12] & $\overline{5.6}$ & $\overline{0.36}$ & $\overline{45.3}$ & 5 & 132 \\
\hline & $\mathrm{Ni}_{50} \mathrm{Mn}_{34} \mathrm{In}_{14} \mathrm{Ga}_{2}$ & 260 & 9.0 & $\underline{0.59}$ & $\overline{73.0}$ & 2.0 & $\overline{2.3}$ & $\overline{0.15}$ & $\overline{18.7}$ & 5 & 133 \\
\hline & $\mathrm{Ni}_{45.2} \mathrm{Mn}_{36.7} \operatorname{In}_{13} \mathrm{Co}_{5.1}$ & 317 & $\underline{18}$ & $\underline{1.16}$ & $\underline{142}$ & 6.2 & $\underline{5.7}$ & $\underline{0.37}$ & $\underline{45.0}$ & 2 & 93 \\
\hline & $\mathrm{CoMnSi}$ & 250 & 6.5 & $\underline{0.31}$ & 41.8 & 1.7 & $\underline{1.6}$ & $\overline{0.08}$ & $\overline{10.3}$ & 5 & 134 \\
\hline & $\dagger \mathrm{Fe}_{49} \mathrm{Rh}_{51}$ & 308 & $\overline{[20]}$ & {$[\overline{1.60}]$} & {$[\overline{202]}$} & 13 & {$[\overline{6.1}]$} & {$[\overline{0.49}]$} & {$[\overline{61.7}]$} & 2 & 14 \\
\hline & $\dagger \mathrm{Fe}_{49} \mathrm{Rh}_{51}$ & 308 & 13 & 1.04 & 131 & 8.3 & 3.9 & 0.31 & 39.4 & 2.5 & 56 \\
\hline
\end{tabular}

† annealed in vacuum at $1300 \mathrm{~K}$ for $72 \mathrm{~h}$, then quenched to $278 \mathrm{~K}$ $\dagger \dagger$ annealed in vacuum at $1273 \mathrm{~K}$ for $10 \mathrm{~h}$, then quenched to $273 \mathrm{~K}$ 
Table S2. Mass, molar and volume normalized electrocaloric effects at phase transitions near and away from room temperature. Isothermal entropy change $\mid \angle$ adiabatic temperature change $|\Delta T|$, and isothermal heat $|Q|$, at starting temperature $T$, due to changes of electric field $|\Delta E|$. For molar normalization, atoms were coun without consideration of species. Volume-normalized data were calculated from mass-normalized values using values of density if available, or lattice parame otherwise. Bold entries denote data derived from direct measurements. Underlined entries denote data derived from indirect measurements. Bracketed entries denote $\mathrm{d}$ derived via $-c \Delta T \approx T \Delta S=Q$ using zero-field specific heat capacity $c$. For all entries, $Q=T \Delta S$. For independently measured isothermal processes, starting temperatures $\mathrm{n}$ differ slightly from the values shown. All starting fields were zero, except for $\mathrm{PbZr}_{0.95} \operatorname{Ti}_{0.05} \mathrm{O}_{3}$ where $E_{\mathrm{i}}=296 \mathrm{kV} \mathrm{cm}^{-1}$. Relaxors are denoted (r).

\begin{tabular}{|c|c|c|c|c|c|c|c|c|c|c|c|}
\hline & EC material & $\begin{array}{l}T \\
\mathrm{~K}\end{array}$ & $\begin{array}{c}|\Delta S| \\
\mathrm{J} \mathrm{K}^{-1} \mathrm{~kg}^{-1}\end{array}$ & $\begin{array}{c}|\Delta S| \\
\mathrm{J} \mathrm{K}^{-1} \mathrm{~mol}^{-1}\end{array}$ & $\begin{array}{c}\quad|\Delta S| \\
\mathrm{kJ} \mathrm{K}^{-1} \mathrm{~m}^{-3}\end{array}$ & $\begin{array}{c}|\Delta T| \\
\mathrm{K}\end{array}$ & $\begin{array}{c}|Q| \\
\mathrm{kJ} \mathrm{kg}^{-1}\end{array}$ & $\begin{array}{c}|Q| \\
\mathrm{kJ} \mathrm{mol}^{-1}\end{array}$ & $\begin{array}{c}|Q| \\
\mathrm{J} \mathrm{cm}^{-3}\end{array}$ & $\begin{array}{c}|\Delta E| \\
\mathrm{kV} \mathrm{cm}^{-1}\end{array}$ & Ref. \\
\hline \multirow{11}{*}{ 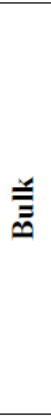 } & $\mathrm{KH}_{2} \mathrm{PO}_{4}$ & 123 & $\underline{3.5}$ & $\underline{0.06}$ & 8.2 & {$[1.0]$} & $\underline{0.4}$ & $\underline{0.01}$ & $\underline{0.94}$ & 10 & 71 \\
\hline & $\mathrm{PbZr}_{0.455} \mathrm{Sn}_{0.455} \mathrm{Ti}_{0.09} \mathrm{O}_{3}$ & 317 & [1.8] & {$[0.13]$} & {$[14.0]$} & 1.6 & {$[0.6]$} & {$[0.04]$} & {$[4.68]$} & 30 & 46 \\
\hline & $\mathrm{PbSc}_{0.5} \mathrm{Ta}_{0.5} \mathrm{O}_{3}$ & 291 & {$[2.1]$} & {$[0.15]$} & {$[19.0]$} & 1.8 & {$[0.6]$} & {$[0.04]$} & {$[5.44]$} & 25 & 78,135 \\
\hline & $\mathrm{BaTiO}_{3}$ & 397 & 2.1 & 0.10 & 12.6 & {$[0.9]$} & 0.8 & 0.04 & 4.82 & 4 & 49 \\
\hline & (r) $\mathrm{Ba}_{0.65} \mathrm{Sr}_{0.35} \mathrm{Ti}_{0.997} \mathrm{Mn}_{0.003} \mathrm{O}_{3}$ & 293 & $\underline{4.8}$ & $\underline{0.21}$ & $\underline{27.3}$ & [3.1] & $\underline{1.4}$ & $\underline{0.06}$ & $\underline{7.97}$ & 130 & 79 \\
\hline & (r) $0.87 \mathrm{PMN}-0.13 \mathrm{PT}$ & 343 & {$[0.6]$} & {$[0.03]$} & {$[4.58]$} & 0.6 & {$[0.2]$} & {$[0.01]$} & {$[1.53]$} & 24 & 136 \\
\hline & (r) $0.75 \mathrm{PMN}-0.25 \mathrm{PT}$ & 383 & 1.0 & 0.06 & 7.64 & {$[1.1]$} & 0.4 & 0.02 & 3.06 & 25 & 137 \\
\hline & (r) $\doteqdot 0.70 \mathrm{PMN}-0.30 \mathrm{PT}$ & 429 & {$[2.3]$} & {$[0.14]$} & {$[17.6]$} & 2.7 & {$[1.0]$} & {$[0.06]$} & [7.64] & 90 & 82 \\
\hline & (r) $\dagger \dagger 0.90 \mathrm{PMN}-0.10 \mathrm{PT}$ & 400 & {$[3.2]$} & {$[0.19]$} & [24.5] & 3.5 & [1.3] & {$[0.08]$} & [9.93] & 160 & $\ddagger$ \\
\hline & $*$ PNZS & 434 & {$[4.3]$} & {$[0.30]$} & [33.5] & 2.6 & [1.9] & {$[0.13]$} & {$[14.8]$} & 30 & 47 \\
\hline & $* *$ PNZS & 423 & [1.7] & {$[0.12]$} & {$[13.3]$} & 2.0 & {$[0.7]$} & {$[0.05]$} & {$[5.46]$} & 20 & 138 \\
\hline \multirow{13}{*}{ 声 } & $\mathrm{PbZr}_{0.95} \mathrm{Ti}_{0.05} \mathrm{O}_{3}$ & 499 & $\underline{8.0}$ & $\underline{0.55}$ & $\underline{62.4}$ & [12] & $\underline{4.0}$ & $\underline{0.27}$ & $\underline{31.2}$ & 480 & 15 \\
\hline & (r) $\mathrm{Pb}_{0.8} \mathrm{Ba}_{0.2} \mathrm{ZrO}_{3}$ & 290 & 47 & $\overline{3.12}$ & $\underline{362}$ & [45] & $\underline{14}$ & $\overline{0.93}$ & 108 & 598 & 139 \\
\hline & (r) $\mathrm{SrBi}_{2} \mathrm{Ta}_{2} \mathrm{O}_{9}$ & 565 & $\overline{2.4}$ & $\overline{0.17}$ & $\overline{21.2}$ & [4.9] & $\overline{1.4}$ & $\underline{0.10}$ & $\underline{12.3}$ & 600 & 140 \\
\hline & (r) $0.90 \mathrm{PMN}-0.10 \mathrm{PT}$ & 348 & $\underline{5.3}$ & $\underline{0.31}$ & $\overline{40.5}$ & {$[5.0]$} & $\overline{1.8}$ & $\overline{0.11}$ & $\overline{13.7}$ & 895 & 141 \\
\hline & (r) $0.93 \mathrm{PMN}-0.07 \mathrm{PT}$ & 298 & $\underline{11}$ & $\underline{0.65}$ & $\underline{84.0}$ & [9.0] & $\underline{3.3}$ & $\underline{0.19}$ & $\underline{25.2}$ & 723 & 142 \\
\hline & (r) $0.65 \mathrm{PMN}-0.35 \mathrm{PT}$ & 413 & $\underline{28}$ & $\underline{1.66}$ & $\underline{214}$ & {$[31]$} & $\underline{11}$ & $\underline{0.65}$ & $\underline{84.0}$ & 747 & 143 \\
\hline & $* \mathrm{P}(\mathrm{VDF}-\mathrm{TrFE})$ & 353 & $\overline{60}$ & $\underline{0.72}$ & $\overline{106}$ & [12.5] & $\underline{21}$ & $\overline{0.25}$ & $\overline{37.2}$ & 2090 & 16 \\
\hline & $* \mathrm{P}(\mathrm{VDF}-\mathrm{TrFE})$ & 340 & {$[\overline{70}]$} & {$[\overline{0.84}]$} & {$[\overline{124}]$} & 12 & [24] & {$[\overline{0.29}]$} & {$[\overline{42.5}]$} & 1200 & 50 \\
\hline & $* * \mathrm{P}(\mathrm{VDF}-\mathrm{TrFE})$ & 390 & $\underline{87}$ & $\underline{1.01}$ & $\underline{154}$ & {$[21]$} & $\underline{34}$ & $\underline{0.39}$ & 60.2 & 3000 & 144 \\
\hline & $* * * \mathrm{P}(\mathrm{VDF}-\mathrm{TrFE})$ & 323 & 130 & 1.52 & 230 & {$[28]$} & 42 & 0.49 & 74.4 & 1800 & 145 \\
\hline & (r) $* \mathrm{P}(\mathrm{VDF}-\mathrm{TrFE}-\mathrm{CFE})$ & 328 & $\underline{64}$ & $\underline{0.76}$ & $\underline{113}$ & {$[12.5]$} & $\underline{21}$ & $\underline{0.25}$ & 37.2 & 3070 & 16 \\
\hline & (r) *P(VDF-TrFE-CFE) & 318 & $\overline{[55}]$ & $\overline{[0.65]}$ & {$[97.3]$} & 12 & {$[17]$} & $\overline{[0.20]}$ & $\overline{[30.1]}$ & 1700 & 51 \\
\hline & $(\mathrm{r}) * * \mathrm{P}(\mathrm{VDF}-\mathrm{TrFE}-\mathrm{CFE})$ & 350 & $\underline{85}$ & $\underline{1.02}$ & $\underline{150}$ & [22] & $\underline{30}$ & $\underline{0.36}$ & $\underline{53.1}$ & 3500 & 144 \\
\hline
\end{tabular}

$\mathrm{PMN}=\mathrm{PbMg} \mathrm{Nb}_{23} \mathrm{O}_{3}, \mathrm{PT}=\mathrm{PbTiO}$

*PNZS $=\mathrm{Pb}_{0.99} \mathrm{Nb}_{0.02}\left(\mathrm{Zr}_{0.75} \mathrm{Sn}_{0.20} \mathrm{Ti}_{0.05}\right)_{0.98} \mathrm{O}_{3}$

$*$ PNZS $=\mathrm{Pb}_{0.99} \mathrm{Nb}_{0.02}\left[\left(\mathrm{Zr}_{0.73} \mathrm{Sn}_{0.27}\right)_{0.93} \mathrm{Ti}_{0.07}\right]_{0.98} \mathrm{O}_{3}$

$* \mathrm{P}(\mathrm{VDF}-\mathrm{TrFE})=$ poly (vinylidene fluoride-trifluoroethylene) $55 / 45 \mathrm{~mol} \%$

**P(VDF-TrFE $)=$ poly (vinylidene fluoride-trifluoroethylene) $70 / 30 \mathrm{~mol} \%$

$* *$ P $(\mathrm{VDF}-\mathrm{TrFE})=$ poly(vinylidene fluoride-trifluoroethylene) $65 / 35 \mathrm{~mol} \%$

$* \mathrm{P}(\mathrm{VDF}-\mathrm{TrFE}-\mathrm{CFE})=$ poly $($ vinylidene fluoride-trifluoroethylene-

chlorofluoroethylene) $59.2 / 33.6 / 7.2 \mathrm{~mol} \%$
$* * \mathrm{P}(\mathrm{VDF}-\mathrm{TrFE}-\mathrm{CFE})=$ poly $($ vinylidene fluoride-

trifluoroethylene-chlorofluoroethylene) 56.2/36.3/7.6 mol\% platelets of thickness 60-100 $\mu \mathrm{m}$

thinned to $80 \mu \mathrm{m}$

†H. Uršič, B. Rožič, Z. Kutnjak, J. Holc, M. Kosec, private communication

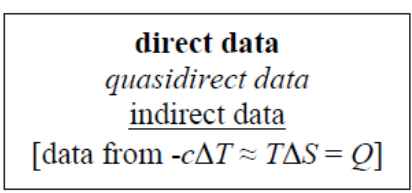


Table S3. Mass, molar and volume normalized mechanocaloric effects at phase transitions near and away from room temperature. Isothermal entropy change $|\Delta S|$, adiabatic temperature change $|\Delta T|$, and isothermal heat $|Q|$, at starting temperature $T$, due to changes of stress field $|\Delta \sigma|$. For molar normalization, atoms were counted without consideration of species. Volume-normalized data were calculated from mass-normalized values using values of density if available, or lattice parameters otherwise. Bold entries denote data derived from direct measurements. Italicised entries denote data derived from quasidirect measurements. Underlined entries denote data derived from indirect measurements. Bracketed entries denote data derived via $-c \Delta T \approx T \Delta S=Q$ using zero-field specific heat capacity $c$. For all entries, $Q=T \Delta S$. For independently measured isothermal processes, starting temperatures may differ slightly from the values shown. All starting fields were zero.

\begin{tabular}{|c|c|c|c|c|c|c|c|c|c|c|c|}
\hline & mC material & $\begin{array}{l}T \\
\mathrm{~K}\end{array}$ & $\begin{array}{c}|\Delta S| \\
\mathrm{J} \mathrm{K}^{-1} \mathrm{~kg}^{-1}\end{array}$ & $\begin{array}{c}|\Delta S| \\
\mathrm{J} \mathrm{K}^{-1} \mathrm{~mol}^{-1}\end{array}$ & $\begin{array}{c}\quad|\Delta S| \\
\mathrm{kJ} \mathrm{K}^{-1} \mathrm{~m}^{-3}\end{array}$ & $\begin{array}{c}|\Delta T| \\
\mathrm{K}\end{array}$ & $\begin{array}{c}|Q| \\
\mathrm{kJ} \mathrm{kg}^{-1}\end{array}$ & $\begin{array}{c}|Q| \\
\mathrm{kJ} \mathrm{mol}^{-1}\end{array}$ & $\begin{array}{c}|Q| \\
\mathrm{J} \mathrm{cm}^{-3}\end{array}$ & $\begin{array}{l}|\Delta \sigma| \\
\mathrm{GPa}\end{array}$ & Ref. \\
\hline \multirow{9}{*}{ U } & $\mathrm{Cu}_{69.6} \mathrm{Al}_{27.7} \mathrm{Ni}_{2.7}$ & 308 & 22 & 1.17 & 152 & 14 & 6.8 & 0.36 & 47.1 & 0.15 & 13 \\
\hline & $\mathrm{Cu}_{68.1} \mathrm{Zn}_{15.8} \mathrm{Al}_{16.1}$ & 300 & $\underline{21}$ & 1.22 & $\underline{162}$ & {$[15]$} & $\underline{6.2}$ & $\underline{0.36}$ & 47.8 & 0.13 & 19 \\
\hline & $\mathrm{Cu}_{64.6} \mathrm{Zn}_{33.7} \mathrm{Sn}_{1.7}$ & 296 & $\overline{15}$ & $\overline{0.98}$ & $\overline{128}$ & 12 & $\overline{4.5}$ & $\overline{0.29}$ & $\overline{38.3}$ & 0.20 & 35 \\
\hline & $\mathrm{NiTi}$ & 295 & {$[\overline{32}]$} & $\overline{[1.70]}$ & {$[\overline{208}]$} & 17 & {$[\overline{9.3}]$} & {$[\overline{0.49}]$} & {$[\overline{60.4}]$} & 0.65 & 36 \\
\hline & $\mathrm{Ni}_{50.1} \mathrm{Ti}_{49.9}$ & 343 & {$[45]$} & {$[2.40]$} & [292] & 28 & {$[15]$} & {$[0.80]$} & [97.5] & 0.90 & 37 \\
\hline & $\mathrm{Ni}_{50.2} \mathrm{Ti}_{49.8}$ & 296 & [74] & [3.94] & [481] & 40 & {$[22]$} & {$[1.17]$} & [143] & 0.80 & 38 \\
\hline & $\mathrm{Ni}_{50.7} \mathrm{Ti}_{49.3}$ & 295 & {$[8.5]$} & {$[0.45]$} & {$[55.2]$} & 11 & {$[2.5]$} & {$[0.13]$} & {$[16.2]$} & 0.03 & 110 \\
\hline & $\mathrm{Fe}_{68.8} \mathrm{Pd}_{31.2}$ & 240 & 4.2 & 0.30 & 37.7 & 2.0 & 1.0 & 0.07 & 8.97 & 0.10 & 86 \\
\hline & $\mathrm{Fe}_{49} \mathrm{Rh}_{51}$ & 311 & {$[\overline{7.8}]$} & {$[\overline{0.62}]$} & {$[\overline{78.9}]$} & 5.2 & {$[2.4]$} & {$[\overline{0.19}]$} & {$[\overline{24.3}]$} & 0.53 & 56,57 \\
\hline \multirow{3}{*}{ U } & $\mathrm{Ni}_{49.26} \mathrm{Mn}_{36.08} \operatorname{In}_{14.66}$ & 293 & 24 & 1.40 & 195 & {$[4.5]$} & 7.1 & 0.41 & 57.8 & 0.26 & 20 \\
\hline & $\mathrm{Gd}_{5} \mathrm{Si}_{2} \mathrm{Ge}_{2}$ & 270 & 11 & 1.21 & 82.5 & 1.1 & 2.9 & 0.32 & 21.7 & 0.20 & 31 \\
\hline & $\mathrm{LaFe}_{11.33} \mathrm{Co}_{0.47} \mathrm{Si}_{1.2}$ & 237 & 8.7 & 0.52 & 64.3 & 2.2 & 2.0 & 0.12 & 14.8 & 0.20 & 32 \\
\hline
\end{tabular}

direct data
quasidirect data
indirect data
$[$ data from $-c \Delta T \approx T \Delta S=Q]$


Table S4. The strength of magnetocaloric effects at phase transitions near and away from room temperature. Isothermal entropy change $|\Delta S|$, adiabatic temperature change $|\Delta T|$, and isothermal heat $|Q|$, at starting temperature $T$, each normalized by the driving magnetic field $\mu_{0}|\Delta H|$. For molar normalization, atoms were counted without consideration of species. Volume-normalized data were calculated from mass-normalized values using values of density if available, or lattice parameters otherwise. Bold entries denote data derived from direct measurements. Italicised entries denote data derived from quasidirect measurements. Underlined entries denote data derived from indirect measurements. Bracketed entries denote data derived via $-c \Delta T \approx T \Delta S=Q$ using zero-field specific heat capacity $c$. For all entries, $Q=T \Delta S$. For independently measured isothermal processes, starting temperatures may differ slightly from the values shown. All starting fields were zero.

\begin{tabular}{|c|c|c|c|c|c|c|c|c|c|c|c|}
\hline & MC material & $\begin{array}{l}T \\
\mathrm{~K} \\
\end{array}$ & $\begin{array}{c}|\Delta S| / \mu_{0}|\Delta H| \\
\mathrm{J} \mathrm{K}^{-1} \mathrm{~kg}^{-1} \mathrm{~T}^{-1}\end{array}$ & $\begin{array}{c}|\Delta S| / \mu_{0}|\Delta H| \\
\mathrm{J} \mathrm{K}^{-1} \mathrm{~mol}^{-1} \mathrm{~T}^{-1} \\
\end{array}$ & $\begin{array}{c}|\Delta S| / \mu_{0}|\Delta H| \\
\mathrm{kJ} \mathrm{K}^{-1} \mathrm{~m}^{-3} \mathrm{~T}^{-1} \\
\end{array}$ & $\underset{\mathrm{K} \mathrm{T}^{-1}}{\left|\Delta T / / \mu_{0}\right| \Delta H \mid}$ & $\left|{ }_{\mathrm{kJ} \mathrm{kg}^{-1} \mathrm{~T}^{-1}}^{\mid}\right| / \mu_{0}|\Delta H|$ & $\underset{\mathrm{kJ} \mathrm{mol}^{-1} \mathrm{~T}^{-1}}{|Q| / \mu_{0} \mid \Delta H}$ & $|Q| / \mu_{\mathrm{J} \mathrm{cm}^{-3} \mathrm{~T}^{-1}}|\Delta H|$ & $\begin{array}{c}\mu_{0}|\Delta H| \\
\mathrm{T}\end{array}$ & Ref \\
\hline \multirow{9}{*}{ 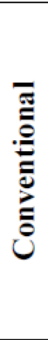 } & Gd & 294 & 2.2 & $\underline{0.35}$ & $\underline{17}$ & 2.6 & $\underline{0.6}$ & $\underline{0.10}$ & $\underline{5.0}$ & 5 & 42 \\
\hline & $\mathrm{Gd}_{5} \mathrm{Si}_{2} \mathrm{Ge}_{2}$ & 280 & $\underline{3.8}$ & $\underline{0.42}$ & 28 & 3.0 & 1.0 & $\underline{0.11}$ & 7.6 & 5 & 17 \\
\hline & MnAs & 317 & $\underline{6.8}$ & $\underline{0.44}$ & $\underline{46}$ & {$[2.6]$} & $\underline{2.2}$ & $\underline{0.14}$ & $\underline{15}$ & 5 & 126 \\
\hline & $\mathrm{MnFeP}_{0.45} \mathrm{As}_{0.55}$ & 308 & $\overline{3.6}$ & $\overline{0.20}$ & $\underline{26}$ & [2.0] & $\overline{1.1}$ & $\overline{0.06}$ & $\underline{8.0}$ & 5 & 127 \\
\hline & $\mathrm{Mn}_{1.24} \mathrm{Fe}_{0.71} \mathrm{P}_{0.46} \mathrm{Si}_{0.54}$ & 320 & $\underline{12}$ & $\underline{0.55}$ & $\underline{87}$ & 3.0 & $\underline{3.9}$ & $\underline{0.18}$ & $\underline{28}$ & 1 & 58 \\
\hline & $\mathrm{MnCoGeB}_{0.02}$ & 277 & $\underline{9.4}$ & $\underline{0.58}$ & $\underline{74}$ & {$[4.8]$} & $\underline{2.6}$ & $\underline{0.16}$ & $\underline{20}$ & 5 & 128 \\
\hline & $\mathrm{LaFe}_{11.57} \mathrm{Si}_{1.43} \mathrm{H}_{1.3}$ & 291 & $\underline{5.6}$ & $\underline{0.33}$ & $\underline{40}$ & 2.6 & $\underline{1.6}$ & $\underline{0.10}$ & $\underline{12}$ & 5 & 67 \\
\hline & $\mathrm{Ni}_{52.6} \mathrm{Mn}_{23.1} \mathrm{Ga}_{24.3}$ & 300 & $\underline{3.6}$ & $\underline{0.22}$ & $\underline{29}$ & {$[2.4]$} & $\underline{1.1}$ & $\underline{0.07}$ & $\underline{8.7}$ & 5 & 129 \\
\hline & $\mathrm{Ni}_{55} \mathrm{Mn}_{20} \mathrm{Ga}_{25}$ & 311 & $\underline{5.8}$ & $\underline{0.35}$ & $\underline{47}$ & 0.4 & $\underline{1.8}$ & $\underline{0.11}$ & $\underline{15}$ & 5 & 130 \\
\hline \multirow{7}{*}{ 总 } & $\mathrm{Ni}_{50} \mathrm{Mn}_{37} \mathrm{Sn}_{13}$ & 299 & $\underline{3.6}$ & $\underline{0.23}$ & $\underline{32}$ & {$[2.4]$} & $\underline{1.1}$ & $\underline{0.07}$ & $\underline{9.7}$ & 5 & 131 \\
\hline & $\mathrm{Ni}_{50} \mathrm{Mn}_{38} \mathrm{Sb}_{12}$ & 297 & $\underline{3.8}$ & $\underline{0.25}$ & $\underline{31}$ & [2.4] & $\underline{1.1}$ & $\underline{0.07}$ & $\underline{9.1}$ & 5 & 132 \\
\hline & $\mathrm{Ni}_{50} \mathrm{Mn}_{34} \mathrm{In}_{14} \mathrm{Ga}_{2}$ & 260 & $\overline{1.8}$ & $\overline{0.12}$ & $\overline{15}$ & 0.4 & $\overline{0.5}$ & $\overline{0.03}$ & $\overline{3.7}$ & 5 & 133 \\
\hline & $\mathrm{Ni}_{45.2} \mathrm{Mn}_{36.7} \mathrm{In}_{13} \mathrm{Co}_{5.1}$ & 317 & $\underline{9.0}$ & $\underline{0.58}$ & $\underline{\overline{71}}$ & 3.1 & $\underline{2.8}$ & $\underline{0.18}$ & $\underline{22}$ & 2 & 93 \\
\hline & $\mathrm{CoMnSi}$ & 250 & $\overline{1.3}$ & $\overline{0.06}$ & $\underline{8.4}$ & 0.3 & $\overline{0.3}$ & $\overline{0.02}$ & $\underline{2.1}$ & 5 & 134 \\
\hline & $\doteqdot \mathrm{Fe}_{49} \mathrm{Rh}_{51}$ & 308 & {$[10]$} & {$[0.80]$} & {$[101]$} & 6.5 & {$[3.0]$} & {$[0.24]$} & {$[31]$} & 2 & 14 \\
\hline & $\doteqdot \mathrm{Fe}_{49} \mathrm{Rh}_{51}$ & 308 & 5.2 & 0.42 & 52 & 3.3 & 1.6 & 0.12 & 16 & 2.5 & 56 \\
\hline
\end{tabular}

Tannealed in vacuum at $1300 \mathrm{~K}$ for $72 \mathrm{~h}$, then quenched to $278 \mathrm{~K}$

$\dagger \dagger$ annealed in vacuum at $1273 \mathrm{~K}$ for $10 \mathrm{~h}$, then quenched to $273 \mathrm{~K}$

direct data
quasidirect data
indirect data
$[$ data from $-c \Delta T \approx T \Delta S=Q]$


Table S5. The strength of electrocaloric effects at phase transitions near and away from room temperature. Isothermal entropy change $|\Delta S|$, adiabatic temperature change $|\Delta T|$, and isothermal heat $|Q|$, at starting temperature $T$, each normalized by the driving electric field $|\Delta E|$. For molar normalization, atoms were counted without consideration of species. Volume-normalized data were calculated from mass-normalized values using values of density if available, or lattice parameters otherwise. Bold entries denote data derived from direct measurements. Underlined entries denote data derived from indirect measurements. Bracketed entries denote data derived via $-c \Delta T \approx T \Delta S=Q$ using zero-field specific heat capacity $c$. For all entries, $Q=T \Delta S$. For independently measured isothermal processes, starting temperatures may differ slightly from the values shown. All starting fields were zero, except for $\mathrm{PbZr}_{0.95} \mathrm{Ti}_{0.05} \mathrm{O}_{3}$ where $E_{\mathrm{i}}=296 \mathrm{kV} \mathrm{cm}^{-1}$. Relaxors are denoted (r).

\begin{tabular}{|c|c|c|c|c|c|c|c|c|c|c|c|}
\hline & EC material & $\begin{array}{l}T \\
\mathrm{~K}\end{array}$ & $\underset{\mathrm{mJ} \mathrm{cm} \mathrm{K}{ }^{-1} \mathrm{~kg}^{-1} \mathrm{kV}^{-1}}{|\Delta S| / \Delta E \mid}$ & $\underset{m \mathrm{~mJ} \mathrm{~cm} \mathrm{~K}^{-1} \mathrm{~mol}^{-1} \mathrm{kV}^{-1}}{|\Delta S| / \Delta E \mid}$ & $\begin{array}{l}|\Delta S| /|\Delta E| \\
\mathrm{J} \mathrm{K}^{-1} \mathrm{~m}^{-2} \mathrm{kV}^{-1}\end{array}$ & $\begin{array}{l}|\Delta T / /| \Delta E \mid \\
\mathrm{mK} \mathrm{cm} \mathrm{kV} V^{-1}\end{array}$ & $\underset{\mathrm{J} \mathrm{cm} \mathrm{kg}^{-1} \mathrm{kV}^{-1}}{|Q| /|\Delta E|}$ & $\underset{\mathrm{J} \mathrm{cm} \mathrm{mol}^{-1} \mathrm{kV}^{-1}}{|Q| / \Delta E \mid}$ & $\underset{\mathrm{mJ} \mathrm{cm}^{-2} \mathrm{kV}^{-1}}{|Q| /|\Delta E|}$ & $\underset{\mathrm{kV} \mathrm{cm}-1}{|\Delta E|}$ & Ref. \\
\hline \multirow{11}{*}{$\stackrel{\underline{\bar{D}}}{\bar{\Delta}}$} & $\mathrm{KH}_{2} \mathrm{PO}_{4}$ & 123 & $\underline{350}$ & 6.0 & 8.2 & {$[100]$} & $\underline{40.0}$ & 1.0 & 94.0 & 10 & 71 \\
\hline & $\mathrm{PbZr}_{0.455} \mathrm{Sn}_{0.455} \mathrm{Ti}_{0.09} \mathrm{O}_{3}$ & 317 & {$[\overline{60.0}]$} & {$[\overline{4.3}]$} & {$[\overline{4.7}]$} & 53.3 & {$[\overline{20.0}]$} & {$[\overline{1.3}]$} & $\overline{[156]}$ & 30 & 46 \\
\hline & $\mathrm{PbSc}_{0.5} \mathrm{Ta}_{0.5} \mathrm{O}_{3}$ & 291 & {$[84.0]$} & {$[6.0]$} & {$[7.6]$} & 72.0 & {$[24.0]$} & {$[1.6]$} & [218] & 25 & 78,135 \\
\hline & $\mathrm{BaTiO}_{3}$ & 397 & 525 & 25 & 32 & {$[225]$} & 200 & 10 & 1205 & 4 & 49 \\
\hline & (r) $\mathrm{Ba}_{0.65} \mathrm{Sr}_{0.35} \mathrm{Ti}_{0.997} \mathrm{Mn}_{0.003} \mathrm{O}_{3}$ & 293 & $\underline{36.9}$ & 1.6 & $\underline{2.1}$ & {$[23.8]$} & $\underline{10.8}$ & $\underline{0.5}$ & $\underline{61.3}$ & 130 & 79 \\
\hline & (r) $0.87 \mathrm{PMN}-0.13 \mathrm{PT}$ & 343 & {$[25.0]$} & {$[1.2]$} & {$[1.9]$} & 25.0 & {$[8.33]$} & {$[0.4]$} & {$[63.7]$} & 24 & 136 \\
\hline & (r) $0.75 \mathrm{PMN}-0.25 \mathrm{PT}$ & 383 & 40.0 & 2.4 & 3.1 & {$[44.0]$} & 16.0 & 0.8 & 122 & 25 & 137 \\
\hline & (r) $\doteqdot 0.70 \mathrm{PMN}-0.30 \mathrm{PT}$ & 429 & {$[25.6]$} & {$[1.6]$} & {$[2.0]$} & 30.0 & {$[11.1]$} & {$[0.7]$} & [84.9] & 90 & 82 \\
\hline & (r) $\dagger \dagger 0.90 \mathrm{PMN}-0.10 \mathrm{PT}$ & 400 & {$[20.0]$} & [1.2] & [1.5] & 21.9 & [8.12] & {$[0.5]$} & [62.1] & 160 & $\grave{\dagger}$ \\
\hline & *PNZS & 434 & {$[143]$} & {$[10]$} & {$[11]$} & 86.7 & {$[63.3]$} & {$[4.3]$} & [493] & 30 & 47 \\
\hline & **PNZS & 423 & [85.0] & {$[6.0]$} & {$[6.7]$} & 100 & {$[35.0]$} & [2.5] & [273] & 20 & 138 \\
\hline \multirow{13}{*}{ 吾 } & $\mathrm{PbZr}_{0.95} \mathrm{Ti}_{0.05} \mathrm{O}_{3}$ & 499 & 16.7 & 1.1 & 1.3 & {$[25.0]$} & 8.33 & 0.6 & 65.0 & 480 & 15 \\
\hline & (r) $\mathrm{Pb}_{0.8} \mathrm{Ba}_{0.2} \mathrm{ZrO}_{3}$ & 290 & $\overline{78.6}$ & 5.2 & 6.1 & {$[75.2]$} & $\overline{23.4}$ & 1.5 & $\overline{181}$ & 598 & 139 \\
\hline & (r) $\mathrm{SrBi}_{2} \mathrm{Ta}_{2} \mathrm{O}_{9}$ & 565 & $\underline{4.00}$ & $\underline{0.3}$ & $\underline{0.3}$ & {$[8.17]$} & 2.33 & $\underline{0.2}$ & 20.5 & 600 & 140 \\
\hline & (r) $0.90 \mathrm{PMN}-0.10 \mathrm{PT}$ & 348 & $\underline{5.92}$ & $\underline{0.3}$ & $\underline{0.4}$ & {$[5.59]$} & 2.01 & 0.1 & 15.3 & 895 & 141 \\
\hline & (r) $0.93 \mathrm{PMN}-0.07 \mathrm{PT}$ & 298 & $\overline{15.2}$ & $\overline{0.9}$ & $\underline{1.2}$ & [12.4] & $\overline{4.56}$ & $\overline{0.3}$ & $\overline{34.8}$ & 723 & 142 \\
\hline & (r) $0.65 \mathrm{PMN}-0.35 \mathrm{PT}$ & 413 & $\overline{37.5}$ & $\underline{2.2}$ & 2.9 & {$[41.5]$} & 14.7 & $\underline{0.9}$ & 112 & 747 & 143 \\
\hline & $* \mathrm{P}(\mathrm{VDF}-\mathrm{TrFE})$ & 353 & 28.7 & $\underline{0.3}$ & 0.5 & {$[5.98]$} & 10.0 & $\underline{0.1}$ & 17.8 & 2090 & 16 \\
\hline & $* \mathrm{P}(\mathrm{VDF}-\mathrm{TrFE})$ & 340 & {$[58.3]$} & {$[0.7]$} & {$[1.0]$} & 10.0 & {$[20.0]$} & {$[0.2]$} & {$[35.4]$} & 1200 & 50 \\
\hline & $* * \mathrm{P}(\mathrm{VDF}-\mathrm{TrFE})$ & 390 & $\underline{29.0}$ & 0.3 & 0.5 & {$[7.00]$} & 11.3 & 0.1 & $\underline{20.1}$ & 3000 & 144 \\
\hline & $* * * \mathrm{P}(\mathrm{VDF}-\mathrm{TrFE})$ & 323 & 72 & $\overline{0.8}$ & $\overline{1.3}$ & {$[15.5]$} & $\overline{23.3}$ & $\overline{0.3}$ & $\overline{41.3}$ & 1800 & 145 \\
\hline & (r) *P(VDF-TrFE-CFE) & 328 & 20.8 & 0.2 & 0.4 & {$[4.07]$} & 6.84 & 0.1 & 12.1 & 3070 & 16 \\
\hline & (r) *P(VDF-TrFE-CFE) & 318 & {$[32.3]$} & {$[0.4]$} & {$[0.6]$} & 7.06 & {$[10.0]$} & {$[0.1]$} & {$[17.7]$} & 1700 & 51 \\
\hline & $(\mathrm{r}) * * \mathrm{P}(\mathrm{VDF}-\mathrm{TrFE}-\mathrm{CFE})$ & 350 & 24.3 & 0.3 & 0.4 & [6.29] & 8.57 & 0.1 & 15.2 & 3500 & 144 \\
\hline
\end{tabular}

$\mathrm{PMN}=\mathrm{PbMg}_{13} \mathrm{Nb}_{23} \mathrm{O}_{3}, \mathrm{PT}=\mathrm{PbTiO}$

$*$ PNZS $=\mathrm{Pb}_{0.99} \mathrm{Nb}_{0.02}\left(\mathrm{Zr}_{0.75} \mathrm{Sn}_{0.20} \mathrm{Ti}_{0.05}\right)_{0.98} \mathrm{O}_{3}$

**PNZS $=\mathrm{Pb}_{0.99} \mathrm{Nb}_{0.02}\left[\left(\mathrm{Zr}_{0.73} \mathrm{Sn}_{0.27}\right)_{0.93} \mathrm{Ti}_{0.07}\right]_{0.98} \mathrm{O}_{3}$

$* \mathrm{P}(\mathrm{VDF}-\mathrm{TrFE})=$ poly (vinylidene fluoride-trifluoroethylene) $55 / 45 \mathrm{~mol} \%$

**P $(\mathrm{VDF}-\mathrm{TrFE})=$ poly $($ vinylidene fluoride-trifluoroethylene $) 70 / 30 \mathrm{~mol} \%$

$* * * \mathrm{P}(\mathrm{VDF}-\mathrm{TrFE})=$ poly(vinylidene fluoride-trifluoroethylene) $65 / 35 \mathrm{~mol} \%$

$* \mathrm{P}(\mathrm{VDF}-\mathrm{TrFE}-\mathrm{CFE})=$ poly $($ vinylidene fluoride-trifluoroethylene-

chlorofluoroethylene) 59.2/33.6/7.2 $\mathrm{mol} \%$
$* * \mathrm{P}(\mathrm{VDF}-\mathrm{TrFE}-\mathrm{CFE})=$ poly $($ vinylidene fluoride-

trifluoroethylene-chlorofluoroethylene) 56.2/36.3/7.6 mol\%

platelets of thickness $60-100 \mu \mathrm{m}$

thinned to $80 \mu \mathrm{m}$

H. Uršič, B. Rožič. Z. Kutnjak. J. Holc, M. Kosec,

private communication

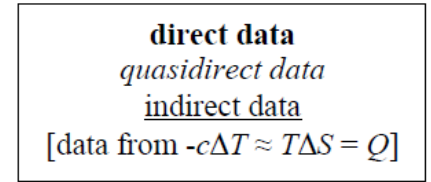


Table S6. The strength of mechanocaloric effects at phase transitions near and away from room temperature. Isothermal entropy change $|\Delta S|$, adiabatic temperature change $|\Delta T|$, and isothermal heat $|Q|$, at starting temperature $T$, each normalized by the driving stress field $\mid \Delta \sigma$. For molar normalization, atoms were counted without consideration of species. Volume-normalized data were calculated from mass-normalized values using values of density if available, or lattice parameters otherwise. Bold entries denote data derived from direct measurements. Italicised entries denote data derived from quasidirect measurements. Underlined entries denote data derived from indirect measurements. Bracketed entries denote data derived via $-c \Delta T \approx T \Delta S=Q$ using zero-field specific heat capacity $c$. For all entries, $Q=T \Delta S$. For independently measured isothermal processes, starting temperatures may differ slightly from the values shown. All starting fields were zero.

\begin{tabular}{|c|c|c|c|c|c|c|c|c|c|c|c|}
\hline & mC material & $\begin{array}{l}T \\
\mathrm{~K}\end{array}$ & $\underset{\mathrm{J} \mathrm{K}^{-1} \mathrm{~kg}^{-1} \mathrm{GP}^{-1}}{|\Delta S| / \Delta \sigma}$ & $\underset{\mathrm{J} \mathrm{K}^{-1} \mathrm{~mol}^{-1} \mathrm{GPa}^{-1}}{|\Delta S| / \Delta \sigma \mid}$ & $\begin{array}{c}|\Delta S| /|\Delta \sigma| \\
\mathrm{MJ} \mathrm{K}^{-1} \mathrm{~m}^{-3} \mathrm{GPa}^{-1}\end{array}$ & $\begin{array}{c}|\Delta T / /| \Delta \sigma \\
\mathrm{K} \mathrm{GPa}^{-1} \\
\end{array}$ & $\underset{\mathrm{kJ} \mathrm{kg}^{-1} \mathrm{GPa}^{-1}}{|Q| /|\Delta \sigma|}$ & $\underset{\mathrm{kJ} \mathrm{mol}^{-1} \mathrm{GPa}^{-1}}{|Q| /|\Delta \sigma|}$ & $\underset{\mathrm{J} \mathrm{cm}^{-3} \mathrm{GPa}^{-1}}{|Q| /|\Delta \sigma|}$ & $\begin{array}{l}|\Delta \sigma| \\
\mathrm{GPa}\end{array}$ & Ref. \\
\hline \multirow{6}{*}{ U } & $\mathrm{Cu}_{69.6} \mathrm{Al}_{27.7} \mathrm{Ni}_{2.7}$ & 308 & 147 & 7.8 & 1.0 & 93 & $\underline{45}$ & 2.4 & $\underline{314}$ & 0.15 & 13 \\
\hline & $\mathrm{Cu}_{68.1} \mathrm{Zn}_{15.8} \mathrm{Al}_{16.1}$ & 300 & $\overline{161}$ & $\overline{9.4}$ & $\underline{1.2}$ & {$[115]$} & $\underline{48}$ & $\underline{2.8}$ & $\underline{368}$ & 0.13 & 19 \\
\hline & $\mathrm{Cu}_{64.6} \mathrm{Zn}_{33.7} \mathrm{Sn}_{1.7}$ & 296 & $\underline{75.0}$ & $\underline{4.9}$ & $\underline{0.6}$ & 60 & $\underline{22}$ & $\underline{1.4}$ & $\underline{191}$ & 0.20 & 35 \\
\hline & $\mathrm{Ni}_{50.1} \mathrm{Ti}_{49.9}$ & 343 & {$[50.0]$} & {$[2.7]$} & {$[0.3]$} & 31 & {$[17]$} & [0.9] & {$[108]$} & 0.90 & 37 \\
\hline & $\mathrm{Ni}_{50.2} \mathrm{Ti}_{49.8}$ & 296 & {$[92.5]$} & [4.9] & {$[0.6]$} & 50 & {$[27]$} & {$[1.5]$} & [179] & 0.80 & 38 \\
\hline & $\mathrm{Ni}_{50.7} \mathrm{Ti}_{49.3}$ & 295 & [283] & {$[15]$} & [1.8] & 367 & [83] & [4.3] & {$[540]$} & 0.03 & 110 \\
\hline \multirow{3}{*}{$\stackrel{\leftrightarrow}{\Perp}$} & $\mathrm{Ni}_{49.26} \mathrm{Mn}_{36.08} \mathrm{In}_{14.66}$ & 293 & 92.3 & 5.4 & 0.7 & {$[17]$} & 27 & 1.6 & 222 & 0.26 & 20 \\
\hline & $\mathrm{Gd}_{5} \mathrm{Si}_{2} \mathrm{Ge}_{2}$ & 270 & 55.0 & 6.0 & 0.4 & 5.5 & 14 & 1.6 & 108 & 0.20 & 31 \\
\hline & $\mathrm{LaFe}_{11.33} \mathrm{Co}_{0.47} \mathrm{Si}_{1.2}$ & 237 & 43.5 & 2.6 & 0.3 & 11 & 10 & 0.6 & 74.0 & 0.20 & 32 \\
\hline
\end{tabular}

direct data
quasidirect data
indirect data
[data from $-c \Delta T \approx T \Delta S=Q]$

